\title{
Sibling correlation in risk attitudes: evidence from Burkina Faso
}

\author{
Mohammad H. Sepahvand ${ }^{1,2}$ (D) Roujman Shahbazian ${ }^{3,4}$
}

Received: 9 February 2019 / Accepted: 21 September 2020 / Published online: 13 November 2020

(C) The Author(s) 2020

\begin{abstract}
This study uses sibling correlation to provide novel descriptive evidence of parental and household characteristics on three different risk domains collected in a nationally representative survey from Burkina Faso. The sibling correlations are between 0.51 and 0.83 . The correlations are higher in the general risk domain compared to risk taking in financial matters and traffic. Moreover, the sibling correlation is higher for sisters than brothers. We also explore which factors might drive these correlations; parents' risk attitudes appears to play a role in explaining these correlations, whereas socioeconomic outcomes, family structure, parental health and residential zone seems to have only a limited contribution. We also find that gender seems to be important in explaining the variation in sibling correlations. Mother's appear to have a stronger contribution on daughters than their sons correlation, whereas father's help to explain their sons correlation.
\end{abstract}

Keywords Risk attitudes · Family background · Sibling correlations · Gender · Burkina Faso

JEL classifications $\mathrm{D} 1 \cdot \mathrm{D} 81 \cdot \mathrm{J} 6 \cdot \mathrm{Z} 1$

\section{Introduction}

In recent decades, measuring risk attitudes as a core determinant of economic behaviour have attracted interest from researchers both in developing countries (e.g., Fafchamps and Pender

Mohammad H. Sepahvand

Mohammad.Sepahvand@nek.uu.se

1 Department of Economics, Uppsala University, Kyrkogårdsgatan 10, Box 513, 75120 Uppsala, Sweden

2 European Center for Advanced Research in Economics and Statistics (ECARES), Université Libre de Bruxelles, Bruxelles, Belgium

3 Swedish Institute for Social Research, Stockholm University, Stockholm, Sweden

4 Department of Sociology, University of Munich (LMU), Munich, Germany 
1997; Harrison et al. 2005; Yesuf and Bluffstone 2009) as well as developed countries (e.g., Brunello 2002; Guiso and Paiella 2005; Dohmen et al. 2011). In developed countries, risk attitudes have been argued to be a mechanism behind intergenerational transmission of socio-economic outcomes such as education, income, wealth and occupation (e.g., Bonin et al. 2007; Dohmen et al. 2012; Björklund et al. 2010). For instance, Lindquist et al. (2016) argue that the risk attitudes of parents are likely an important mechanism that contributes to sibling similarities in the choice of risky occupations, and capturing such variation is suggested to be an important avenue for future research. In a developing context, risk attitudes are of particular interest, since it is generally assumed that individuals are risk averse, thus hindering them in accessing formal credit markets or adopting new technologies. Thereby, understanding the mechanisms that generates and reproduces risk attitudes over time is an important aspect since it affects economic behaviour.

The family is a focal institution that shapes an individual's preferences. The emphasis is usually placed on the parent-child relationship, as indicated by the growing empirical literature on the transmission of attitudes between parents and children such as precautionary behaviour (Yeung et al. 2000), gender-roles (Fernández et al. 2004), family values (Mason 2007), trust and social capital (Tabellini 2008), non-cognitive abilities (Grönqvist et al. 2016) and time devoted to housework (Gimenez-Nadal et al. 2014). Transmission of risk attitudes has been investigated to a much lesser extent. However, there are some exceptions. Kimball et al. (2009) find a positive association between parents and their adult children's risk taking with hypothetical income gambles questions. Dohmen et al. (2012) show evidence for the existence of an intergenerational transmission of risk attitudes with self-reported risk questions. Although there is a tradition in economics and sociology of investigating family influences through intergenerational correlation (e.g., Björklund and Jäntti 1997; Chadwick and Solon 2002; Black et al. 2005; Mood et al. 2012; Blanden et al. 2013; Mood 2017), parental influence is only one of many ways through which individual's preferences are shaped. Besides genetic endowments and parent-child socialization, factors such as neighbourhoods, schools and other institutions may shape the child's choice for instance such as obtaining higher/lower levels of education, employment, income or risk. Therefore, the sibling correlation has been argued to be a broader measure than intergenerational correlation in capturing the influence of family and community background for outcomes in adult life (e.g., Solon et al. 1991; Conley and Glauber 2008; Black and Devereux 2011; Björklund and Jäntti 2012; Aparicio-Fenoll and Oppedisano 2016). The reason is that the sibling correlation has a straightforward interpretation: it is the fraction of the variation in an outcome that can be explained by factors that siblings share. Siblings who have grown up together share the same environment. Thus, the sibling correlation is an omnibus measure of the importance of family background and community effects. Thereby, it captures anything that is shared by siblings both inside and outside the family (such as parental influence and resources but also school, religious institutions and neighbourhood effects), while at the same time capturing anything that is not shared by siblings, (such as genetic traits not shared, different treatment of siblings and changes in neighbourhoods, schools etc.).

There are many different ways to elicit risk preferences (for an overview see Charness et al. 2013). This study uses the same form of self-reported risk questions as used in the German 
Socio-Economic panel (SOEP). These risk questions have been utilized in numerous studies. ${ }^{1}$ Previous research has shown that self-reported risk questions have a high validity ${ }^{2}$ and sufficient reliability. ${ }^{3}$ The importance of reliability and reproducibility of scientific findings has recently been highlighted (e.g., Dreber et al. 2015; Camerer et al. 2016). Self-reported risk questions are a simple and cost-effective way to elicit risk preferences using large scale surveys. These risk measurements can be easily reproduced by other researchers both over time and across countries, in order to deepen our understanding of individual's risk preferences.

By estimating sibling correlations in risk attitudes, we make three contributions to the literature. First, it allows us to measure the overall importance of family and community background as possible determinants of risk attitudes. To the best of our knowledge, only one study has estimated a baseline for the sibling correlation in risk attitudes (Schnitzlein 2014). ${ }^{4}$ Our results indicate that these correlations are larger than previously found based on intergenerational correlation studies on risk attitudes. As we later show, the sibling correlation in risk attitudes for general risk taking drop between $24 \%$ and $29 \%$ when controlling separately for father's and mother's risk attitudes. To put these results in perspective, sibling correlations in criminal behaviour decrease by at most $21 \%$ when controlling for parental criminality (Eriksson et al. 2016).

Second, through the sibling correlation we can explore the relative importance of various determinants, discussed previously in the literature, which seems to have some effect on risk attitudes. Parents' level of education appears to play a role in determining risk attitudes (Dohmen et al. 2011); however, is it relatively important alongside other parental socioeconomic outcomes? How does family structure, such as mother's and father's age at first birth, marital status and parent's religious ideology explain the similarity of siblings? Risk preferences have been suggested to be correlated with risky behaviour (de Walque 2013). Therefore, we investigate whether indicators such as parental health and if parents smoke or not, can explain some of the variation among sibling's risk attitudes.

Third, by measuring the sibling correlation we can gain an understanding of gender specific influences in different risk domains. Sepahvand and Shahbazian (2020b) show support for a gender-specific role model hypothesis in terms of risk attitudes. We therefore investigate the relative importance of fathers' and mothers' associative effect in the financial as well as the traffic risk domain on sibling similarities. Apparently, risk attitudes are highly correlated within families, so policy makers interested in affecting those attitudes should think about the family as a relevant unit of analysis. If interventions on the parents would indeed have a causal spillover effect on their children would need to be confirmed by subsequent research.

\footnotetext{
${ }^{1}$ Such as in China (Ding et al. 2010; Jin et al. 2017), Germany (Dohmen et al. 2011; Lönnqvist et al. 2015), Netherlands (Wölbert and Riedl 2013), Thailand (Hardeweg et al. 2013), Thailand and Vietnam (Liebenehm et al. 2015) and Sweden (Beauchamp et al. 2017).

${ }^{2}$ The self-reported risk questions used in this study, has been proven to capture individuals risk preferences by comparing them to incentivized lottery experiments, in developed countries (e.g., Dohmen et al. 2011; Lönnqvist et al. 2015), emerging countries (e.g., Hardeweg et al. 2013), developing countries and comparatively for 30 countries (Vieider et al. 2015).

${ }^{3}$ The reliability of the self-reported risk questions in this study has been analyzed by Sepahvand and Shahbazian (2020a). They show that the reliability is satisfactory and to a large extent comparable to other studies using the same self-reported risk questions.

${ }^{4}$ Schnitzlein (2014) is the only study, we have been able to find, which computes the sibling correlation for selfreported risk attitudes in Germany in a subsection of their analysis. Schnitzlein (2014) main focus is to analyze the sibling correlation in permanent income, and do not apply the decomposition approach to the sibling correlation in risk attitudes.
} 
We estimate sibling correlations of risk attitudes by using a nationally representative multipurpose Household Budget Survey (HBS) collected from all the 13 regions of Burkina Faso. The HBS was collected in 2014 from 10,800 households. All respondents aged 18 years and older in each household have provided answers to the risk questions, which are the outcome variables for our study. Our analytical sample consists of all adult siblings (at least two per household) who have provided answers to these risk questions and for whom we observe their mother's and father's characteristics.

\section{Burkina Faso}

Burkina Faso as a country of study is of particular interest as it is one of the most economically underdeveloped countries in the world. Thereby, its economic growth is conditioned on to what extent individuals can go from traditional sectors (such as agriculture) to more industrialized and technological ones. Burkina Faso is a landlocked country in West Africa, the agricultural sector constitutes around one third of its gross domestic product (GDP) and occupies around $80 \%$ of the working age population. ${ }^{5}$ In terms of investments, Burkina Faso was ranked as the 111th investment destination in the world, ${ }^{6}$ which makes investments in the country a risky choice. Due to the climate, most of the population of Burkina Faso are concentrated in the centre and south of the country, which is also why the northern regions are the poorest regions (INSD 2015a). On average, there are approximately six children born per woman in Burkina Faso with a life expectancy estimated to be between 57 and 59 years old (INSD 2015b). The relatively large amount of births per women in relation to population projections for 2014 of almost 18 million inhabitants (INSD 2017) makes the country's population growth one of the highest in the world.

In sub-Saharan African countries, there is a great need for individuals to take risk in order to reach unforeseen opportunities, such as adopt new technologies or venture into new occupations. However, in many of these countries, such as Burkina Faso, the institutions are still underdeveloped and access to social services is scarce. The political climate is highly volatile and structural transformations are low in the Burkina Faso, resulting in constant pressure on the labour markets and infrastructure (e.g., Sepahvand 2019). In such harsh conditions of uncertainty about the imminent future, investments are impeded. Thus, risk-taking behaviour may be of particular importance to explain economic as well as social behaviour on the individual level in the country.

Further, there are inequalities in terms of who has access to scarce services in Burkina Faso. Those who need social services the most (the poor in rural areas) have the least access to it (INSD 2015a). This has led to rapid urbanization. In addition, estimates show that around 50\% of the population is under 20 years old (INSD 2015b). Despite that, the educational sectors share of GDP has increased and overall poverty was around 40\% in 2014 (INSD 2015a), the age demographic trend together with the large share of urbanization will increase the competition for urban jobs, which creates challenges for the institutions to create more opportunities in the urban non-agricultural occupational sector. As the formal financial services and social security are scarce or underdeveloped in Burkina Faso, the family, as an institution, becomes an important arena for shaping individuals risk taking, in particular the transmission from

\footnotetext{
${ }^{5}$ Ministry of Agriculture Burkina Faso, found at http://agriculture-bf.info/ (2018-04-22).

${ }^{6}$ Euromoney Country Risk, http://www.euromoneycountryrisk.com (2018-03-10).
} 
parents to children, as children observe and pay attention to their surrounding and might imitate that behavior.

In sub-Saharan African countries, such as Burkina Faso, with strong gender norms, there are several elements that make it more likely that this transmission of risk attitudes within the family might be gendered. For instance, girls and boys reproduce the behavior the society (and/or their nearest environment) considers appropriate for their gender. Burkinabé children are more likely to imitate the risk attitudes of their parents if they are similar to one other, i.e. have the same sex (Sepahvand and Shahbazian 2020b). The underlying factor is that, if children view their same-sex parent performing a distinct set of activities, they will be more likely to model their own behavior and attitudes after those exhibited by the parents. In Burkinabé families, men tend, to a larger extent, go on long trips (for migration and/or seasonal work) and work longer periods outside of the household. Women conduct more of the household work and work that is in close proximity of the household. They are also more likely to be involved in care labor (e.g., to prepare the meal, take care of the children, collect water). Therefore, both girls and boys are more likely to be exposed to traffic when accompanied by their fathers than mothers. When it comes to financial transactions, women usually manage the daily financial transactions, such as buying groceries at the market (most likely accompanied by the children). ${ }^{7}$ Thus, predicting that fathers exert a relatively stronger influence in traffic on their daughters than they do in financial matters and mothers have a relatively stronger influence in financial matters on their sons than they do in traffic.

\section{Data and analytical sample}

Our study is based on a multipurpose Household Budget Survey (HBS). ${ }^{8}$ The HBS is a faceto-face, nationally representative panel survey covering 900 enumeration areas (EA) ${ }^{9}$ with 12 households per EA, i.e., 10,800 households spread across the 13 regions of Burkina Faso (INSD 2013). ${ }^{10}$

This study focuses on three different risk questions in the HBS that directly ask the respondent to assess his or her willingness to take risks in traffic, in financial matters and in

\footnotetext{
${ }^{7}$ Men manage larger but less-frequent financial transactions, such as buying a house or motorcycle.

${ }^{8}$ The main purpose of the HBS is to evaluate whether Burkina Faso has achieved the UN millennium goals, which is why each household is interviewed in four rounds during 2014. The HBS was conducted as a government cooperation project between the National Institute of Statistics and Demography (INSD, Institut National de la Statistique et de la Démographie) of Burkina Faso and Statistics Sweden (SCB), which provided the technical assistance. The project was financed by the Swedish International Development Cooperation Agency (Sida, or in French: Agence suédoise de coopération internationale au développement, Asdi). One of the Authors was living in Burkina Faso, in charge of this bilateral technical aid project in statistics.

${ }^{9}$ The enumeration area is a statistical defined geographical unit for sampling purpose. The selection of the EAs is a random selection, including both urban and rural areas. A two-stage stratified sampling technique is used. In the first stage, the EAs are drawn from a frame with a probability proportional to the number of households in the EA. The frame constitutes of 13,821 mapped EAs defined during the population census of 2006 . Then a listing procedure is conducted in each drawn EA in order to update the number of households, i.e., the frame of the second stage. In the second stage, 12 households per EA are drawn with equal probability in each EA.

${ }^{10}$ For more information on the data see Sepahvand (2019).
} 
general. These self-reported risk attitude questions were collected in the third (July-September) and fourth (October-December) rounds of 2014 as a separate module for all household members with the age of 18 years and older. ${ }^{11}$ The overall household response rate was approximately $95 \%$ for the third and fourth round respectively, which gives us a low level of attrition. We have adopted the same self-reported risk questions as those from the German Socio-Economic Panel, which have been used extensively in previous studies, and have also been empirically validated through field experiments as being a fruitful way of eliciting a reliable measurement of risk preferences (Dohmen et al. 2011; Hardeweg et al. 2013; Vieider et al. 2015; Lönnqvist et al. 2015; Beauchamp et al. 2017). The exact English wording of the questions is as follows: "How do you see yourself: Are you a person who is fully prepared to take risks or do you try to avoid taking risks? On a scale from 1 to 10 , where $1=$ not at all willing to take risk and $10=$ very willing to take risk. A. In traffic (driving a car, motorcycle, bike, etc.), B. In financial matters, C. In general?"

All respondents aged 18 years and older have answered all three risk questions. However, not all respondents answered at both time points. The number of responses in the 3 rd round was 34,494 , in 4th round were 33,066 and in both rounds by the same individuals is 31,677 for all three risk questions. In order to get a more reliable measurement of risk attitudes and decrease measurement error, the analysis in this study use the average of the two periods. However, all analysis was performed with responses separately for the 3rd and 4th round and the results are similar. ${ }^{12}$

Since we use a household survey, the siblings must live within the household. Therefore, there might be a suspicion that siblings who live in the household are a selective group. In a sub-Saharan African country such as Burkina Faso, a traditionally agricultural society with undeveloped public security mechanisms, it is common that the children who grow up in the household stay in the same household and take over the responsibility of the extended household (e.g., Cattell 1990; Peil 1995; Canning et al. 2015). It is not uncommon that the parents continue to live in the household, now as the child's responsibility. Usually those children that take over the responsibility of a household, including the parents' living conditions, are the sons. Thus, men within our data would not be a selective group. Women, due to the patriarchal norms that shape gender roles in a sub-Saharan African country such as Burkina Faso tend to leave the household that they grew up in after their marriage to live in their husband's household (e.g., Newman 1984). Early marriage is a phenomenon that affects girls disproportionally compared to boys, the median age at marriage for women in subSaharan Africa is around 18 years old (Koski et al. 2017). Child marriage is also evident in Burkina Faso; almost $10 \%$ of first marriages occurs before age 15 years. ${ }^{13}$ This is also indicated by Table 5 in the Appendix, as we have a lower share of daughters in the sample. There could potentially be a selection issue with those daughters that we observe in our sample, i.e. for instance those that stay in the household have different risk aversion than those that leave or compared to other members of the household. We compare as sensitivity tests the mean value of risk attitudes for daughters and other female non-relatives in the same household. The average risk attitudes for daughters (female non-relatives) are 3.9 (4.0) for

\footnotetext{
${ }^{11}$ The interviewers were instructed to ask all individual question separately and alone with the respondent, as there are other sensitive individual questions asked separately such as questions about sexual practices and domestic violence.

${ }^{12}$ Results available upon request.

${ }^{13}$ UNICEF report access at https://www.unicef.org/media/files/Child_Marriage_Report_7_17_LR..pdf (201812-15).
} 
risk taking in general, 3.4 (3.3) for risk taking in traffic and 4.3 (4.2) for risk in financial matters. As another sensitivity test we compare the mean value of women in our analytical sample to all other women that have answered our risk attitude questions. The difference between the analytical sample women (other women) is 3.7 (3.6), 2.9 (2.7) and 4.3 (4.2) for risk taking in general, traffic and financial matters. We see the same pattern but with higher mean values when doing the same comparison for men. When comparing the mean value for risk attitudes of unmarried daughters and sons living in the same household, we get a correlation of 0.97 . These tests give us an indication that the daughters in our sample are not a selective group.

\subsection{Descriptive statistics and variables}

In order to be included in the analytical sample, respondents must be 18 years and older, and have at least one sibling in the household. It includes those siblings that are the children of the head of the household. ${ }^{14}$ Our analytical sample consist of 1849 siblings. It includes those siblings where we observe both of their parents' risk attitudes in all three risk domains as well as provided information on their socio-economic status, family structure, health and residential zone in both survey rounds.

We now turn to a first descriptive look of our outcome and main explanatory variables, and then we turn our attention to a set of exploratory variables of different parental and household characteristics, as illustrated in Table 5 in the Appendix that shows the descriptive statistics of siblings for our analytical sample (Sample 2), including subsamples of brothers and sisters. ${ }^{15}$

The age distribution in our analytical sample is overwhelming younger, $78 \%$ are between 18 and 29 years old. Our sample includes more male than female siblings. Turning the attention to the main explanatory variables, comparing mothers to fathers in our analytical sample, fathers seems to take on average more risk than mothers in all risk domains.

Our measures of parental socio-economic status include level of education, employment status, household consumption, access to a bank account and household size. We use mother's and father's level of education separately. Education level is given by four categories: Low, Primary, Secondary education and University. ${ }^{16}$ The majority of parents have a low level of education, over $75 \%$, whereas mothers are less educated than fathers. The consumption variable, include the household's overall consumption in $\mathrm{FCFA}^{17}$ for the entire year (all the

\footnotetext{
${ }^{14}$ In addition, we also have access to those siblings that are the brother or sister of the head of the household, a so called older generations of siblings (included in Sample 3). One important distinction with this group of siblings is that we have limited information about their parents. The division between this group and or analytical sample that constitute a relatively younger generation of siblings allows us to calculate the sibling correlation for the whole age distribution in Burkina Faso, and also capture different mechanisms that play a role between siblings from a younger and older generation (i.e., different generations). For estimates of sibling correlations of younger and older generation, see Table 2 in Sepahvand and Shahbazian (2018).

${ }^{15}$ Most previous research has shown that boys are more risk taking than girls (e.g., Cárdenas et al., 2012), and women more risk averse than men (e.g., Donkers et al. 2001; Croson and Gneezy 2009; Andersson et al. 2016). However, some literature do not find any difference between men and women (e.g., Harrison et al. 2005; FraserMackenzie et al. 2014) or criticizes the line of research that claim to have found gender differences in risk attitudes (Nelson 2016).

${ }^{16}$ In those instances where there is a missing value on father's or mother's level of education (which is more common for the oldest respondents), we have coded them into the Low education category.

${ }^{17}$ FCFA, franc CFA is the currency used in Burkina Faso and some other West and Central African countries. CFA stands for Communauté Financière Africaine. The exchange rate with the euro is fixed (1 euro $=655.957$ $\mathrm{XOF})$.
} 
four rounds) of 2014, divided into food and non-food consumption. A variable is also included for if mothers and fathers have a bank account, there exists a larger fraction of mothers in our analytical sample with no bank account compared to fathers.

Another category of variables relates to family structure. These variables include mother's and father's age at first birth, both parents' religion and marital status. Mother's and father's age at first birth are treated as categorical variables: 13-19, 20-29, 30-39 and 40 years and older. The mother's and father's religion are categorical variables including the following categories: Catholic, Muslim, Protestant and Animism. The martial status variable includes four categories: if the mothers or fathers are single, married, divorced or widowed.

Our third category of exploratory variables is related to parents' health, which includes an indicator whether the mother or father have been sick during the past 15 days. There is also information on parents' smoking habits, if they smoke or not.

Our indicator variables indicating residential zone, include measures of whether siblings live in an urban or a rural area. In a country such as Burkina Faso there are differences between rural and urban areas. For instance, common family, school and neighbourhood effects shared by the siblings could differ in an urban setting which might have less strong gender norms compared to a rural setting, affecting the strength of socialization within the family.

\section{Empirical methodology}

In order to calculate the sibling correlation in risk attitudes, $\rho$, estimates of the within-family variation, $\sigma_{b}^{2}$, and the between-family variation, $\sigma_{a}^{2}$, is needed to be estimated. We follow the same procedure as previous research (e.g., Björklund et al. 2010; Lindquist et al. 2016), and estimate this variation by using a mixed-effects model. We have modified it so that to measure the sibling correlation for risk attitudes. ${ }^{18}$

\subsection{Sibling correlation}

We start by having a measure for our outcome variable risk attitude, denoted by $r_{i j}$, for sibling $j$ in family $i$. The risk attitudes are then modelled as follows:

$$
r_{i j}=\mathrm{X}_{i j}^{\mathrm{T}} \beta+\varepsilon_{i j},
$$

where the vector, $\mathrm{X}_{i j}^{\mathrm{T}}$, include gender and age dummies and other control variables that we will come to later on below. These dummies are treated as fixed effects. The residual term, $\varepsilon_{i j}$, is an individual-specific component representing an individual's position in the overall distribution of risk taking, whose population variance is given by $\sigma_{\varepsilon}^{2}$. The residual, $\varepsilon_{i j}$, is decomposed as follows ${ }^{19}$ :

$$
\varepsilon_{i j}=a_{i}+b_{i j}
$$

\footnotetext{
${ }^{18}$ The distributional assumptions of mixed effects model do make sense for our outcome variable, as our risk variable measure an (assumable) continuous underlying variable. In our case, we asked respondents to self-assess their risk attitudes on a scale from 1 to 10 . However, risk attitudes may be considered continuous in nature.

${ }^{19}$ The $\varepsilon_{i j}$ is assumed to consist of two linearly additive and independent variance components (Solon 1999).
} 
The terms on the right hand side of Eq. (2) are treated as random effects; $a_{i}$ is a permanent component shared by all siblings in family $i$, what makes siblings similar, and $b_{i j}$ is a permanent component unique to sibling $j$ in family $i$. These terms are uncorrelated by construction with each other. This fact is important for us, as it allows us to divide the permanent component into a part that is perfectly shared by all siblings in the family $\left(a_{i}\right)$ and a part that is perfectly uncorrelated and hence unique among siblings $\left(b_{i j}\right)$. The variance of $\varepsilon_{i j}$ is then

$$
\sigma_{\varepsilon}^{2}=\sigma_{a}^{2}+\sigma_{b}^{2}
$$

The first term, $\sigma_{a}^{2}$, captures the variance in the permanent risk attitudes that is due to difference between families. The second term, $\sigma_{b}^{2}$, captures the variance in the permanent risk attitudes within families. These two components are then used to calculate the correlation in the permanent risk attitudes between siblings, $\rho$, which is the main focus of our analysis in this study.

$$
\rho=\frac{\sigma_{a}^{2}}{\sigma_{a}^{2}+\sigma_{b}^{2}} \equiv \operatorname{corr}\left(\varepsilon_{i j}, \varepsilon_{i j^{\prime}}\right) .
$$

Equation (4) shows the fraction of the overall variance of the permanent component that is due to shared family and community background. Or put differently, it makes it clear that the sibling correlation, $\rho$, is the share of the variance in children's risk attitudes that can be attributed to the common family background factors. It provides an estimate of the correlation in risk attitudes among the siblings in a randomly selected household from the population.

We can estimate the sibling correlation in risk attitudes, $\rho$ of Eq. (4), by using estimates of the between-family variation, $\sigma_{a}^{2}$, and the individual within-family variation, $\sigma_{b}^{2}$. These can be obtained by estimating the following mixed-effects model:

$$
r_{i j}=\mathrm{X}_{i j}^{\mathrm{T}} \beta+a_{i}+b_{i j}
$$

where gender and age dummies for siblings are included in $\mathrm{X}_{i j}^{\mathrm{T}}$ as a baseline. We estimate Eq. (5) using Stata's mixed command. ${ }^{20}$ The variance components are estimated using maximum likelihood. Thus, a nice feature of the mixed-effect model is that it directly produces standard errors of the variance components (allowing us to obtain $\rho$ ). ${ }^{21}$

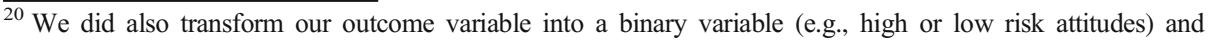
estimated Eq. (5) using Stata's melogit command following the same procedure as Lindquist et al. (2016). This provided similar estimates of the sibling correlation as using the mixed command. Results available upon request. ${ }^{21}$ As part of Stata's mixed command's standard output it is possible to get $\rho$ with a 95\% confidence interval, which does not suffer from small sample bias (Björklund et al. 2010). A disadvantage of these mixed-effects models might be that they do not have closed-form solutions and rely on numerical optimization techniques. However, following the same procedure, as Lindquist et al. (2016), we experiment with estimation commands using slightly different optimization procedures. For example, using the Stata gllamm command (Rabe-Hesketh et al. 2005) gives similar estimates. Results available upon request.
} 
A sibling correlation can therefore be viewed as the consequence of "common genes, common environment, or the influence of one brother on the other" Jencks et al. (1979:10). Thereby, it includes any social or genetic traits shared by siblings, such as parental resources, parental influence (for instance cultural and ethical inheritance or aspirations), genetics and experiences at place of worship (e.g., mosque or church), neighbourhood and school. Any genetic or social traits which are not shared by the siblings, would be captured by the individual component $b_{i j}$. If these nonshared factors are relatively more important than shared factors for risk attitudes, the variance of the family effect will be small relative to the variance of the individual effect. Thereby leading to the sibling correlation, $\rho$ in Eq. (4), being low. In the other case, the more important the effect that sibling do share are, $a_{i}$, the larger is the sibling correlation.

In order to explain some of the household-level variance in risk attitudes between siblings it is possible to incorporate household-level predictors into the model. For example, gender of the siblings, their age and level of education (their own and parents) may determine individual's risk attitudes in Burkina Faso. Therefore, we would be able to investigate how much of what the siblings share is captured by adding covariates to $\mathrm{X}_{i j}^{\mathrm{T}}$ in Eq. (1), and examine if these characteristics generate any difference in sibling correlations. This would be done through creating different categories of variables from parental and household characteristics we expect to affect the sibling risk correlation. Thereby, we would be able to detect what variables that appears to play a role in determining risk attitudes through $a_{i}$, meaning how much of the sibling similarities in risk attitudes they account for. As baseline, our sibling correlations include controls for the age and gender of the sibling. This decomposition approach has been used by the previous literature examining what could determine sibling similarities in various outcomes such as income (e.g., Björklund et al. 2010), cognitive and non-cognitive skills (e.g., Anger and Schnitzlein 2017), earnings and wages (e.g., Mazumder 2008) and criminal behaviour (e.g., Hederos Eriksson et al. 2016), it has not been used to descriptively investigate the determinants of sibling similarities in risk attitudes. To illustrate our decomposition approach, consider for instance the inclusion of mother's and father's risk attitudes in $\mathrm{X}_{i j}^{\mathrm{T}}$. These two additional variables should reduce the residual variation in sibling's risk attitudes and produce a lower estimate of the between-family variation, $\sigma_{a}^{2 *}$, than the estimate produced at baseline without adding these two controls, $\sigma_{a}^{2}$. We can interpret the difference between these two estimates, $\sigma_{a}^{2}-\sigma_{a}^{2 *}$, as an upper bound on the amount of variance in the family component that can be explained by parent's risk attitudes. It is considered an upper bound as it includes other mechanism/factors influencing children's risk attitudes that are correlated with parent's risk attitudes, such as gender, education, religion, health, residential zone. This decomposition approach will also produce a new sibling correlation, $\rho^{*}$. Since there exist a strong intergenerational transmission of risk attitudes in Burkina Faso (Sepahvand and Shahbazian 2020b), we expect this new sibling correlation to be much lower than then one obtained at baseline, $\rho$. As this is the first study examining sibling similarities in risk attitudes, the degree to which a control variable lowers the sibling correlation after being included provides a metric for judging its importance in explaining sibling similarities. However, this does not allow us to make a causal interpretation. 


\subsection{Comparison to the intergenerational transmission of risk}

In order to show the relationship between intergenerational transmission, which we will call $\beta$, and the sibling correlation in risk attitudes, $\rho$, we need to extend our modelling framework in section 4 above. ${ }^{22}$ The family component in Eq. (2) can be decomposed into one part due to parental risk attitudes $r_{i}$ and one part due to other factors which are uncorrelated with parental risk attitudes, $z_{i}$ :

$$
a_{i}=\beta r_{i}+z_{i} \text {. }
$$

Substitution into Eq. (1) gives

$$
r_{i j}=\mathrm{X}_{i j}^{\mathrm{T}} \delta+\beta r_{i}+\varepsilon_{i j},
$$

where the residual, $\varepsilon_{i j}$, is decomposed as follows:

$$
\varepsilon_{i j}=z_{i}+b_{i j}
$$

Equation (7) is the intergenerational regression of child risk on parental risk. Taking variance on both sides of Eq. (6) and dividing by total variance in risk, $\sigma_{r}^{2}$, gives.

$$
\frac{\sigma_{a}^{2}}{\sigma_{r}^{2}}=\beta^{2}+\frac{\sigma_{z}^{2}}{\sigma_{r}^{2}} .
$$

The left-hand side of Eq. (9) is identical to the sibling correlation as defined in Eq. (4). Equation (9) shows that the sibling correlation is proportional to the squared intergenerational coefficient in risk attitudes. Equation (9) also shows that the sibling correlation captures additional family background factors that are not capture by intergenerational correlation. Thus, Eq. (9) makes it clear that sibling correlation is a broader measure because it captures the effects of parental risk attitudes and also other common family and neighbourhood factors shared by the children, but not correlated with parental risk attitudes. This is empirically shown by previous research. Mazumder (2008) and Björklund et al. (2010) indicate in the context of income mobility that more than half of the family backgrounds and community effects that siblings share do not correlate with their parents' income. Further, Emran and Shilpi (2015) show that the proportion of sibling correlation in educational attainment explained by intergenerational correlation is around 50 to $55 \%$.

\section{Empirical result}

In this section, we investigate the sibling correlation for risk taking. To do this, we start by examining what the baseline estimates are and then continue with how parental and other household characteristics explain the variation in sibling correlations. We also examine sibling correlations for brothers and sisters, and compare our results with previous research on intergenerational correlation in risk attitudes.

${ }^{22}$ Follow the same procedure as previous research (e.g. Solon 1999; Adermon and Gunnarsson 2017; Lindquist et al. 2016). 


\subsection{Results for parents' risk attitudes}

What is it that makes the risk attitudes of siblings so similar? Previous research finds empirical support for an intergenerational correlation of risk attitudes in Burkina Faso (Sepahvand and Shahbazian 2020b), hence we expect parents risk attitudes to explain the variation in sibling risk correlation. In Table 1 panel B-D we estimate this for the siblings, and by including mother's, father's and both parents' risk attitudes as controls to our baseline correlation estimation method. ${ }^{23}$

When controlling for both parents' risk attitudes, the sibling correlation for risk taking in general drops by $32 \%$ from 0.76 to 0.52 . This indicates that parents' risk attitudes have a strong associative relationship on the sibling correlation. When including mother's and father's risk attitudes in general separately, we detect a drop in the estimated sibling risk correlations by $29 \%$ from mothers and $24 \%$ from fathers. ${ }^{24}$ This provides an initial indication that there might be some heterogeneity in terms of gender. Moreover, these magnitudes of the importance of parents' risk attitudes echo those that would be expected from previous estimates of sibling correlations in income, education and crime for Sweden and Denmark. Björklund et al. (2010) found an $18 \%$ reduction in the sibling correlation in income after controlling for father's occupation. Bredtmann and Smith (2016) show that controlling separately for mother's (father's) occupation decreases the sibling correlation in completing upper secondary education by $23 \%$ (21\%). Hederos Eriksson et al. (2016) study the different factors that could potentially explain why siblings are similar in terms of their criminal behaviour. Their results imply that sibling associations in criminal behaviour decrease by at most $21 \%$ when controlling for parental criminality.

Traffic is a more male-dominated domain, while financial matters is a more femaledominated domain in Burkina Faso. ${ }^{25}$ The strong association detected from mother's risk taking on the sibling correlation in general risk attitudes is reversed for sibling risk correlation in traffic. Instead, in the risk domain of traffic, the father's risk attitudes accounts for a larger percentage drop than mothers: $24 \%$ from fathers compared to $20 \%$ from mothers. However, in the more female-dominated risk domain (i.e., risk in financial matters), mothers seem to

\footnotetext{
${ }^{23}$ We use standardized version of the risk measures in all the tables, in order to have a transparent comparison of coefficients with future studies. The standardization is conducted separately of the child's, the mother's and the father's risk attitudes, for the sample where the child and both parents have answered all risk questions in both survey rounds. Our results do not include any singletons or polygamous households. Further, our analytical sample only includes those siblings where we observe their parents' risk attitudes in all three risk domains as well as their socio-economic status, family structure, health and residential zone. For baseline estimates of sibling correlations in risk attitudes for samples with siblings without parents (Sample 3, but also Sample 1) see Table 2 in Sepahvand and Shahbazian (2018).

${ }^{24}$ Sibling risk correlation in general drops with $29 \%$ to 0.54 when controlling separately for mother's risk attitudes. This drop is more compared to when controlling separately for father's risk attitude, which drops the sibling risk correlation in general by $24 \%$ to 0.58 .

${ }^{25}$ Men tend to larger extend go on long trips (for migration and/or seasonal work) and work longer periods outside of the household. Women conduct more of the household work and work which is in close proximity of the household. They are also more likely to stay home when it is dark outside (to prepare the meal, take care of the children etc.) and if they go out they tend to not do it alone. Therefore, both girls and boys are more likely to be exposed to traffic when accompanied with their fathers than mothers. When it comes to financial transactions the opposite applies. For instance women are usually in charge of the daily financial transactions, such as buying groceries at the market (most likely accompanied by the children). Men are more in charge of larger but less frequent financial transactions, such as buying a house and motorcycle. Thereby, predicting that fathers exert a relatively stronger influence in traffic on their daughters than they do in financial matters, and mothers exert a relatively stronger influence in financial matters on their sons than they do in traffic.
} 
Table 1 Baseline estimation for siblings, and controlling for mothers and fathers risk attitudes

\begin{tabular}{|c|c|c|c|c|c|c|c|c|c|}
\hline \multicolumn{4}{|c|}{ Traffic } & \multicolumn{3}{|c|}{ Financial } & \multicolumn{3}{|c|}{ General } \\
\hline \multicolumn{10}{|c|}{ Panel A. Baseline estimates. } \\
\hline \multirow{3}{*}{$\begin{array}{l}\text { Sibling corr. } \\
\text { s.e. }\end{array}$} & & \multirow{2}{*}{\multicolumn{2}{|c|}{$\begin{array}{l}0,72 \\
(0,02)\end{array}$}} & & \multirow{2}{*}{\multicolumn{2}{|c|}{$\begin{array}{l}0,64 \\
(0,02)\end{array}$}} & & \multirow{2}{*}{\multicolumn{2}{|c|}{$\begin{array}{l}0,76 \\
(0,01)\end{array}$}} \\
\hline & & & & & & & & & \\
\hline & & $\downarrow$ & $\% \downarrow$ & & $\downarrow$ & $\% \downarrow$ & & $\downarrow$ & $\% \downarrow$ \\
\hline \multicolumn{10}{|c|}{ Panel B. Mother's risk attitudes. } \\
\hline $\begin{array}{l}\text { Sibling corr. } \\
\text { s.e. }\end{array}$ & $\begin{array}{l}0,57 \\
(0,02)\end{array}$ & 0,15 & $20 \%$ & $\begin{array}{l}0,57 \\
(0,02)\end{array}$ & 0,06 & $9 \%$ & $\begin{array}{l}0,54 \\
(0,02)\end{array}$ & 0,22 & $29 \%$ \\
\hline \multicolumn{10}{|c|}{ Panel C. Father's risk attitudes. } \\
\hline $\begin{array}{l}\text { Sibling corr. } \\
\text { s.e. }\end{array}$ & $\begin{array}{l}0,55 \\
(0,02)\end{array}$ & 0,17 & $24 \%$ & $\begin{array}{l}0,60 \\
(0,02)\end{array}$ & 0,04 & $6 \%$ & $\begin{array}{l}0,58 \\
(0,02)\end{array}$ & 0,18 & $24 \%$ \\
\hline \multicolumn{10}{|c|}{ Panel D. Mother's \& Father's risk attitudes. } \\
\hline $\begin{array}{l}\text { Sibling corr. } \\
\text { s.e. }\end{array}$ & $\begin{array}{l}0,51 \\
(0,03)\end{array}$ & 0,21 & $29 \%$ & $\begin{array}{l}0,56 \\
(0,03)\end{array}$ & 0,08 & $12 \%$ & $\begin{array}{l}0,52 \\
(0,03)\end{array}$ & 0,24 & $32 \%$ \\
\hline
\end{tabular}

Shows coefficient estimates for the sibling correlation in traffic, financial and general risk attitudes. The analytical sample $(n=1849)$ uses the average risk attitude of the sibling between round 3 and 4 as the dependent variable. The sibling characteristics of gender and age are added to the vector $\mathrm{X}_{i j}^{\mathrm{T}}$ in Eq. (5) for the baseline estimates (in all tables). The mother's and father's average risk attitudes between the 3rd and 4th round are included separately and jointly as the main explanatory variables. $\downarrow$ gives the absolute decrease in the sibling correlation. \% gives the percentage decrease. Standard errors in parentheses are clustered at the household level. The mean difference between mother's and father's risk attitudes is statistically significantly different to zero

explain more of the variation in sibling correlations than fathers, as the siblings risk correlation in financial matters drops by $9 \%$ from including mother's risk attitudes, compared to only $6 \%$ from father's risk attitudes.

\subsection{Results for brothers and sisters}

Previous research has given support to the gender-specific role model hypothesis in terms of risk attitudes: since there are strong gender roles in Burkina Faso, the transmission of attitudes from mothers have a stronger associative effect on their child in the female dominated domain, and for fathers the effect is reverse (Sepahvand and Shahbazian 2020b). Therefore, we will investigate if sibling risk correlation depends on the siblings' gender, ${ }^{26}$ and the gender of the parents.

Table 2 shows the risk correlation for brothers and sisters. Looking at our baseline estimates of sibling risk correlation in panel $\mathrm{A}$, the difference between brother and sister correlations are different across risk domains. Sisters have a higher correlation in risk than brothers across all the three risk domains. Our estimate for brothers' and sisters' correlation of risk attitudes in general is higher than previous estimates for Germany (Schnitzlein 2014), which is the only previous estimate we have found for comparing our baseline of the sibling correlation in risk attitudes. ${ }^{27}$

\footnotetext{
${ }^{26}$ There is a well-established literature looking at brothers and sisters correlation within various outcomes, such as earnings (e.g., Björklund et al. 2002; Conley and Glauber 2008), income (e.g., Björklund et al. 2009; Jäntti and Jenkins 2015), education (e.g., Benin and Johnson 1984;; Holmlund 2005) and cognitive and non-cognitive skills (e.g., Anger and Schnitzlein 2017).

27 We have also investigated the sibling correlation for mixed brother-sister pairs. Our results indicate that the correlation in risk attitudes for traffic, financial matters and in general between mixed sibling pairs is smaller than same gender sibling pairs. This in line with previous research comparing the sibling correlation for mixed- and same gender pairs within various outcomes such as years of schooling (e.g., Björklund and Jäntti 2020). Results available upon request.
} 
Schnitzlein (2014), applying the same measure of self-reported risk taking as our measure, estimate brothers' correlation to 0.40 and sisters' correlation in risk attitudes to 0.36 . The fact that there is a higher correlation in risk attitudes within the family in Burkina Faso than Germany has also been found in previous studies. Sepahvand and Shahbazian (2020b) focusing on intergenerational transmission of risk attitudes show that the estimates for Burkina Faso are higher compared to those found by Dohmen et al. (2012) for Germany, using the same risk measurements.

For risk taking in general, Table 2 panel $\mathrm{B}$ and $\mathrm{C}$ shows descriptive evidence that mothers have a stronger effect on sisters and fathers have a stronger effect on brothers' correlation. Moreover, Table 2 panel B and C shows strong gender heterogeneity within the risk domains of financial matters and traffic. We see that when controlling only for mother's risk attitudes in the female dominated risk domain (i.e., financial matters), the drop in the sisters' correlation in risk attitudes is higher compared to when controlling only for father's risk attitudes. The drop in the brothers' correlation in financial risk taking is similar when controlling only for mothers $(4 \%)$ or fathers $(3 \%)$.

In the male dominated risk domain of traffic, brothers' correlation in risk drops by $16 \%$ when controlling for fathers compared to $11 \%$ when controlling for mothers. Indicating that fathers seems to have a stronger effect on sons' risk taking compared to mothers. But interestingly, mothers seem to explain more of the variation for sisters' correlation in traffic than fathers, as sisters' correlation drops by $23 \%$ when controlling only for mothers compared to a drop of $17 \%$ when including only fathers.

It should be noted that the effect of fathers on sisters seems to still be relatively high, and the father's effect for both brothers and sisters is quite similar. Overall, these descriptive findings could give additional support to the gender-specific role model hypotheses in terms of risk attitudes within the family.

\subsection{Results for parental \& household characteristics}

To further investigate what other parental and household characteristics that appears to play a role for sibling similarities in risk attitudes, we include three broad categories with indicators alongside parental risk attitudes one at a time and simultaneously as controls. These are socioeconomic status, family structure and parental health indicators.

Table 3 shows that the sibling correlation drops the most when controlling for parents' risk attitudes, with $29 \%$ for traffic, $12 \%$ for financial and $32 \%$ for general. It can also be noted that none of the three other broad categories of indicators has a strong association with risk attitudes. $^{28}$

\subsection{Results for urban/rural}

As many sub-Saharan African countries are facing large urbanization, with urban areas soon constituting most of the society, we are interested in exploring if there are any differences in

\footnotetext{
${ }^{28}$ We have also investigated neighborhood correlations with this data set. The results are consistent with the theory of transmission of attitudes that a channel of transmission of attitudes exists from the neighborhood (defined as EA:s) on the child's risk attitudes. However, in line with previous research it does not affect the transmission of attitudes between parents and children. Therefore, we did not include these neighborhood estimates in this paper, but they are available in Sepahvand and Shahbazian (2020b) Table 5.
} 


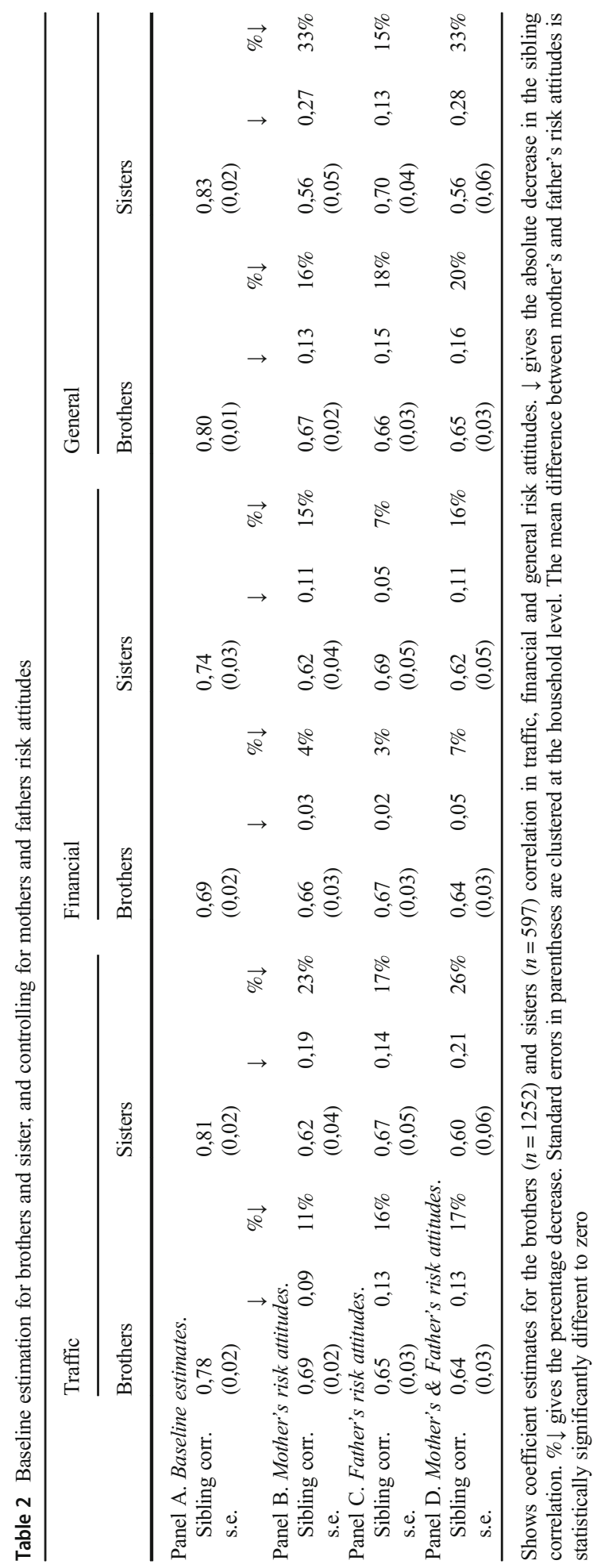


Table 3 Baseline estimation for siblings, and controlling for four broad categories of indicators

Traffic Financial General

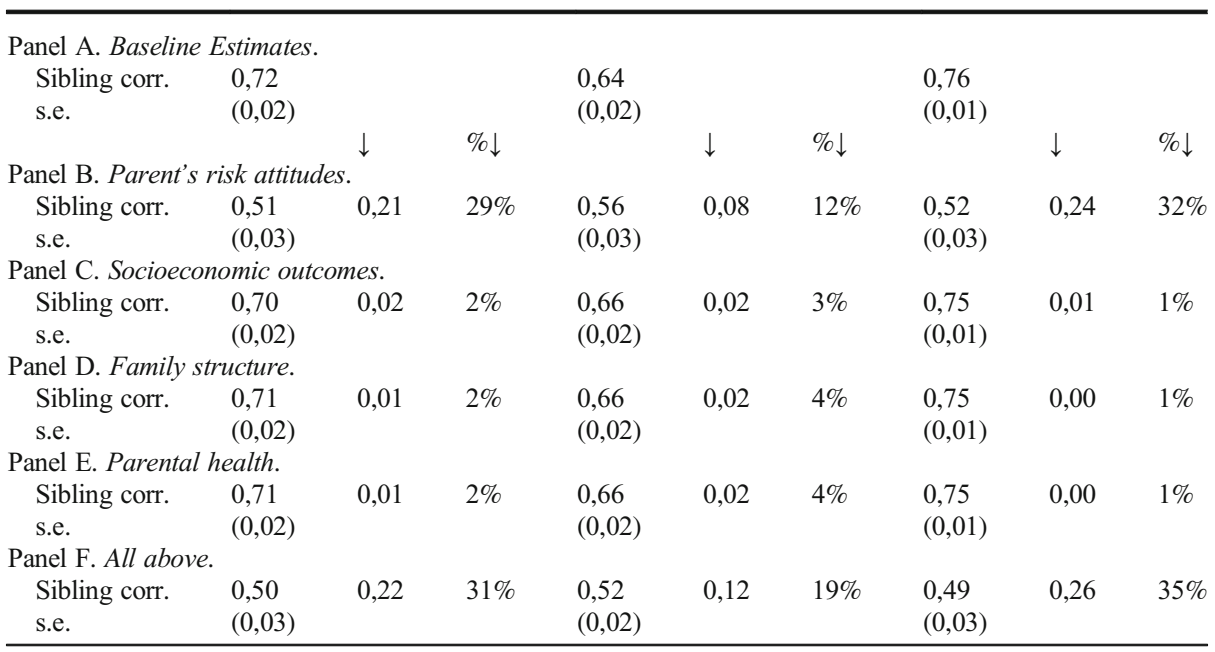

Shows coefficient estimates for the sibling correlation in traffic, financial and general risk attitudes. Socioeconomic status, Family structure and Parental health are included as separate controls in the analytical sample $(\mathrm{n}=$ 1849). $\downarrow$ gives the absolute decrease in the sibling correlation. $\% \downarrow$ gives the percentage decrease. Standard errors in parentheses are clustered at the household level. The mean difference between each different groups of control compared to parent's risk attitudes is statistically significantly different to zero

sibling similarities between rural and urban areas. Table 4 shows that when controlling for rural and urban area, the sibling correlation for risk taking decrease almost by the same percentage points (between 1 to $2 \%$ ) for all three risk domains. ${ }^{29}$

\subsection{Comparison to the intergenerational transmission of risk}

A key question to address is how our estimates of sibling correlation compare to estimated intergenerational correlation in risk attitudes. It is considered a fact, as stated earlier above, that according to previous literature and conceptually sibling correlation is related to intergenerational correlation, but that it is a broader measure of mobility. However, there are only a few papers in the existing literature that have adopted sibling correlation as a measure in the context of developing countries, and non to the best of our knowledge in terms of risk attitudes. Thereby, it is important to investigate if intergenerational correlations in risk attitudes can account for most of the sibling correlation, or are other shared factors uncorrelated with parental risk attitudes most important. This would allow us to empirical understand if we can regard intergenerational- and sibling correlations as two different kind of measurements of

\footnotetext{
${ }^{29}$ Brothers and sisters correlations could also differ between an urban and rural setting. For instance, common family, school and neighborhood effects shared by the siblings could differ in an urban setting which might have less strong gender norms compared to a rural setting, affecting the strength of socialization. We find indications that when controlling for rural, it explains a higher percentage drop in sister correlation compared to when controlling for urban. However, we do not have enough statistical power for the sample of sister $(n=597)$ that allows us to split it into an urban and rural subsample and state that the differences is statistically significant. Further, the urban and rural area does not affect the transmission of attitudes between parents and children, which still seems to be the strongest, as indicated by Table 3 .
} 
Table 4 Baseline estimation for siblings, and controlling for living in urban or rural area

\begin{tabular}{|c|c|c|c|c|c|c|c|c|c|}
\hline \multicolumn{4}{|c|}{ Traffic } & \multicolumn{3}{|c|}{ Financial } & \multicolumn{3}{|c|}{ General } \\
\hline \multicolumn{10}{|c|}{ Panel A. Baseline estimates. } \\
\hline Sibling corr. & & 0,72 & & & 0,64 & & & 0,76 & \\
\hline s.e. & & $(0,02)$ & & & $(0,02)$ & & & $(0,01)$ & \\
\hline & & $\downarrow$ & $\% \downarrow$ & & $\downarrow$ & $\% \downarrow$ & & $\downarrow$ & $\% \downarrow$ \\
\hline \multicolumn{10}{|l|}{ Panel B. Urban. } \\
\hline $\begin{array}{l}\text { Sibling corr. } \\
\text { s.e. }\end{array}$ & $\begin{array}{l}0,72 \\
(0,01)\end{array}$ & 0,00 & $1 \%$ & $\begin{array}{l}0,63 \\
(0,02)\end{array}$ & 0,00 & $0 \%$ & $\begin{array}{l}0,75 \\
(0,01)\end{array}$ & 0,01 & $1 \%$ \\
\hline \multicolumn{10}{|l|}{ Panel C. Rural. } \\
\hline $\begin{array}{l}\text { Sibling corr. } \\
\text { s.e. }\end{array}$ & $\begin{array}{l}0,71 \\
(0,02)\end{array}$ & 0,01 & $1 \%$ & $\begin{array}{l}0,66 \\
(0,02)\end{array}$ & 0,01 & $2 \%$ & $\begin{array}{l}0,75 \\
(0,01)\end{array}$ & 0,01 & $2 \%$ \\
\hline
\end{tabular}

Shows coefficient estimates for the sibling correlation in traffic, financial and general risk attitudes. The residential zone (Urban or Rural) are included separately as explanatory variables in the analytical sample $(\mathrm{n}=1849)$. $\downarrow$ gives the absolute decrease in the sibling correlation. $\% \downarrow$ gives the percentage decrease. Standard errors in parentheses are clustered at the household level. The mean difference between urban and rural is statistically significantly different to zero

mobility in risk-taking for developing countries, and if so, consider sibling correlations as a broader measure.

Sepahvand and Shahbazian (2020b) has estimated the intergenerational correlation of risk attitudes in Burkina Faso using the same risk measurements. A comparison of the intergenerational correlation estimates reported and discussed in Table 1 in Sepahvand and Shahbazian (2020b) with the estimated sibling correlations reported in Table 1 above clearly shows a considerable gap between the intergenerational correlation and sibling correlation in risk attitudes. Thus, other factors that siblings share, uncorrelated with parental risk attitudes, seems to be important. For example, Sepahvand and Shahbazian (2020b) estimate an intergenerational transmission from mother's (father's) risk attitudes towards their child of 0.36 $(0.33)$ for general, $0.22(0.45)$ for traffic and $0.33(0.22)$ for risk in financial matters. According to Eq. (9) in section 4.1 it would imply a squared intergenerational correlation estimate corresponding to $0.13(0.11)$ for general, $0.05(0.20)$ for traffic and $0.11(0.05)$ for risk in financial matters. These are much lower than our sibling correlations in Table 1, which shows that controlling for mother's (father's) risk attitudes gives a sibling correlation of $0.54(0.58)$ for risk in general, $0.57(0.55)$ for risk in traffic and $0.57(0.60)$ for risk in financial matters. This could indicate that family background factors uncorrelated with parental risk might be important for the formation of child risk (i.e., the second term on the right-hand side of Eq. (9)). These considerable gaps between the intergenerational correlations and the sibling correlations in risk attitudes are in line with estimates from developed countries. For instance in a paper where they discuss different approaches to study how income and schooling depend on family background, Björklund and Jäntti (2020) shows that an intergenerational correlation in parental income in Sweden of 0.175 implies a squared intergenerational correlation of 0.031 to be compared with a sibling correlation of around 0.30 . The corresponding numbers for years of schooling are a squared intergenerational correlation of 0.09 and a sibling correlation of 0.43 .

These results show that beside what can be explained by parental risk factors, shared background factors seems to explain a large variation for siblings' risk formation. Thus, it implies that the concept of intergenerational correlation emphasizes the deviations between parents' and their offspring's in shaping risk attitudes, whereas the concept of sibling 
correlation learns about the role of family (and neighbourhood) background on risk formation. Both of these approaches are informative about important questions and provide a richer picture of the role of family background on the formation of risk attitudes. However, estimates of sibling correlations in risk attitudes show that there is much more in family and community background than what intergenerational correlations estimates indicate. Thus, the sibling correlation in risk attitudes can serve as an important benchmark against which intergenerational correlation estimates can be compared. This allows us to understand what is it that siblings share but that is not accounted for by parental risk attitudes.

\section{Discussion}

The associative findings of the high sibling correlation in risk attitudes in this paper might also be relevant for other literature. Previous research shows correlations between risk attitudes and education (e.g., Guiso and Paiella 2005; Brunello 2002), entrepreneurship (e.g., Cramer et al. 2002; Caliendo et al. 2009) and occupation (e.g., Bonin et al. 2007). A large body of research has shown strong persistence in outcomes such as income, education, occupational choice and entrepreneurship across generation and emphasis that shared family background provides an additional channel which makes children to end up with similar outcomes partly because they have been under similar influence and thus make the same patterns of choices.

What is it that families and communities give children that make them so similar in terms of risk attitudes? The estimates of the sibling correlation in risk attitudes in this paper, might provide some answers to this question. Our decomposition approach, shows that parental characteristic, in particular parents' risk attitudes seems to be positively correlated with siblings' risk attitudes. When controlling for both parents' risk attitudes, their contribution to the sibling correlations are $32 \%$ for general, $29 \%$ for traffic and $12 \%$ for risk taking in financial matters. These magnitudes of the drop in the sibling correlations for risk attitudes is in line with the previous estimations from developed countries of sibling correlation such as criminal behaviour (e.g., Hederos Eriksson et al. 2016), education (e.g., Bredtmann and Smith 2016) and income (e.g., Björklund et al. 2010). By contrast, other parental and household characteristics such as socioeconomic status, family structure, parental health and residential zone seems to account for small shares of the sibling correlations in risk attitudes.

Although our results do give some guidance for researchers and policy makers to investigate the role of parental involvement and attitudes in more detail in sub-Saharan countries such as Burkina Faso, there is still a need for casual evidence before direct policy implications can be implemented. However, as indicated by Emran and Shilpi (2019), estimating causal effects is challenging because one needs credible exogenous variation in the parental generation (for instance randomized interventions when they are in school) and then to track down and collect information on all of the siblings when they grow up to avoid sample truncation. A less demanding approach is to focus on sibling correlations, which provides a broader measure of mobility (compared to for example intergenerational correlations) which is particularly useful with limited data such as in the case of Burkina Faso. Further, according to Björklund and Jäntti (2020) siblings do not only share parental resources of the types that are considered in intergenerational correlation literatures. Siblings also share several important factors that are hard to observe (e.g., aspirations and cultural inheritance). Usually these factors are not available in typical household surveys from developing countries and are difficult to collect 
even with very ambitious research efforts, which makes sibling correlations an ideal measurement of mobility in developing countries.

Our estimates of the sibling correlation in risk attitudes seems to be high, in particular in relation to intergenerational correlations in risk attitudes. A substantial literature in the context of developed countries use sibling correlations as a broader measure of intergenerational correlations that captures both observable and unobservable family and neighborhood effects shared by siblings which shape their economic opportunities later in the life. Thus, implying a higher value of sibling correlations by default (e.g., Solon et al. 1991; Mazumder 2008; Björklund et al. 2010). Another possible explanation could be that estimates of sibling correlations are higher in developing countries than in developed countries, due to market imperfections, especially credit constraints in developing countries. ${ }^{30}$ In developing countries, there is a great need for individuals to take risk in order to reach unforeseen opportunities, such as investing in education of a child. ${ }^{31}$

Our panel survey only contains co-resident siblings, which could be a potential source of co-resident bias in the analytical sample used to estimate sibling correlations. Emran and Shilpi (2019) presents a detailed and excellent framework of how to deal with co-residence bias in sibling correlations in developing countries. According to them, a sample of co-resident children is more likely to provide a credible estimate of the sibling correlation because it would capture the common family, school, and neighbourhood effects shared by them. In contrast, non-resident children who no longer live at home, since say 5-10 years, for instance due to migration or education decisions (e.g., Dustmann et al. 2017), may not share many of the common factors as the neighbourhood and schools change with time. Thus, missing such non-resident children from the sample is most likely less damaging for the estimations of sibling correlations or any other measure of family background. In fact, recent unpublished estimates for India, Bangladesh and China suggest that bias due to sample truncation because of co-residence is significantly low in the estimation of sibling correlation (Emran et al. 2020). In addition, emerging evidence from developing countries show that the bias in intergenerational correlation is significantly small and less sensitive to the co-residency rate (Emran et al. 2018). Emran et al. (2018) is primarily concerned with the truncation due to the fact that the sample does not contain all the children of household head when some children leave the household for higher study or migration work (sons) or marriage (daughters). Hopefully, with these recent findings, more papers may adopt sibling correlation as a measure in the context of developing countries as it is a broader measure that better captures family and neighborhood effects shared by siblings. However, evidence from developing countries on the effects of

\footnotetext{
${ }_{30}$ This argument follows the same reasoning as Becker and Tomes (1986), where economic analysis of intergenerational mobility has credit constraints as the main source of intergenerational persistence (see also Emran and Shilpi 2015 on the role of credit constraints in intergenerational mobility in developing countries).

${ }^{31}$ Consider the case of education: every household in a perfect market faces the same wages in the labor market and the same interest rate in the credit market. Thus, the parents, irrespective of the family a child is born into, optimally invest in education of a child. This implies that the accident of birth plays a marginal role in educational attainment, which makes the family component low. Now, assume that there are two social groups, the poor and the rich. The poor pay higher interest rates because of credit market imperfections, which is the case in developing countries. These higher interest rates, given cognitive ability, implies that the poor parents invest less in education of a child. Thus, compared to the case of perfect credit markets, the average education level of children born into a randomly drawn poor household is lower. This implies that the variance of the family component is larger, due to these differences in credit constraints between poor and rich groups in developing countries, hence making the sibling correlation higher. As compared to developed countries where there are relatively less of market imperfections and hence less differences in credit constraints between poor and rich groups.
} 
truncation due to parents level of education and son preferences in future estimates of sibling (and intergenerational) correlations would be valuable.

\section{Conclusion}

This study focuses on the sibling correlation for a sub-Saharan African country, Burkina Faso. The institutional setting, in particular the lack of strong institutions and the important role of the family is an important trait for many developing countries that faces huge challenges ahead. The majority of previous research on sibling correlations has focused on various economic outcomes that are likely to hold for developed countries, with strong institutions and different degrees of social security. This study helps to fill the gap in the literature in understanding economic decision making in developing countries. As our risk measurement is fairly easy and cost-effective for researchers and practitioners to implement in other countries with the same setting, it allows for comparison over time and across countries. This is important, since recently replicability and reproducibility of scientific findings have remerged as a salient factor (Dreber et al. 2015; Camerer et al. 2016), by being able to use and analyse the same measures as previous studies.

This study explored which and how much of parent's and the household characteristics matter for explaining sibling similarities in risk attitudes. We extend the literature on the parent-child transmission of risk attitudes, by using a broader measure in capturing family and community effects, i.e., the sibling correlation, which to the best of our knowledge has not be shown before for risk attitudes. ${ }^{32}$ The measurement of sibling correlations in risk attitudes is important in understanding how risk attitudes are shaped and is the main contribution of this study. When comparing our results to previous research on the intergenerational transmission of risk attitudes, we detect that the sibling correlation shows that parents' willingness to take risk seems to play a role in shaping risk attitudes but that there is more than just parents' risk taking that plays a role. Controlling for parents' risk taking reduces the sibling correlation at most by $33 \%$. However, shard background factors besides parents' risk attitudes constitutes approximately $60 \%$ of the correlation among sibling's risk taking. It is an empirical question to understand what these other factors are and be able to quantify their descriptive effect on sibling similarities.

To explore the heterogeneity that might exist in sibling correlations, we have estimated sibling correlations across three different risk domains, and for brothers and sisters separately. Our analyses address both the literature on gender differences in risk attitudes and the emerging debate in economics about the integration of individual-difference psychology into economics (e.g., Almlund et al. 2011; Borghans et al. 2008) where the argument is that risk attitudes are domain specific (e.g., Weber et al. 2002; Dohmen et al. 2011; Beauchamp et al. 2017). Our descriptive findings indicate that more of the similarities of siblings in risk attitudes seems to be due to shared family backgrounds and community effects in the risk domains of traffic and general compared to financial matters. Brothers have a lower sibling correlation than sisters, in all the three risk domains.

\footnotetext{
${ }^{32}$ Although Schnitzlein (2014) estimates a baseline for the sibling correlation in risk attitudes in a subsection of his study. His does not analyze the importance of family background and community effects, such as mother's and father's risk attitudes, education, income, occupation and residential zone.
} 
Why are sibling correlations different for different risk domains? Previous research on risk attitudes in Burkina Faso has shown that the transmission of attitudes from mother to child is different from father to child if it takes place in a female or male-dominated risk domain. In the more male dominated risk domain of traffic, fathers account for a larger contribution to the sibling correlation than mothers. The pattern is reversed for the sibling correlation in the more female dominated risk domain of financial matters. Mothers account for $9 \%$ to the sibling correlation compared to the contribution from fathers, which is $6 \%$. Furthermore, we also see that mothers' contribution to sisters' correlation in the more female dominated risk domain of financial matters is stronger compared to the fathers'. In the maledominated risk domain of traffic, we see the reverse pattern, including only father's risk attitudes drop the brother correlation by $16 \%$ compared to the mother's contribution, which accounts for $11 \%$. However, the descriptive effect of fathers on sisters is still relatively high in traffic. This seems to support the gender-specific role model hypothesis in terms of risk attitudes.

The results in this paper are not without limitations. Most importantly, when trying to understand the determinants of sibling similarities, we cannot claim that we have causal estimates. Our results are rather a part of an exploratory descriptive approach that give indications of those factors that can and cannot explain the main share of sibling similarities. In addition, since we analyse to which extent siblings are similar, per default we cannot claim that our results hold for single-child families. However, since Burkina Faso is one of the countries in the world with the highest fertility rate, six children per mother (INSD 2015b), single-child families are a silent factor. Future avenues for research can be to first validate these results for risk attitudes to other countries in order to detect country-specific effects, in particular when it comes to gender roles. Second, future studies could examine if different parenting style has an influence on sibling similarities. Third, genetics might play an important role in shaping risk attitudes, however, the magnitude of it is an empirical question that must and should be addressed by future research.

Acknowledgments We have benefited greatly from comments on previous versions by Ranjula Bali Swain, Anders Björklund, Matthew J. Lindquist, Björn Öckert, Mathias von Buxhoeveden and discussions with ChuanZhong Li, Emma von Essen, Ola Andersson, Adrian Adermon, Daniel Spiro and the seminar participants at the Uppsala University Department of Economics in December 2017. We gratefully acknowledge the National Institute of Statistics and Demographics (INSD, Institut National de la Statistique et de la Démographie) in Burkina Faso for collecting the data used in this study, and the anonymous referees for their constructive comments. All remaining errors are our own.

Funding Open access funding provided by Uppsala University.

\section{Compliance with ethical standards}

Conflict of interest The authors declare that they have no conflict of interest.

Ethical approval All procedures performed in studies involving human participants were in accordance with the ethical standards of the institutional and/or national research committee and with the 1964 Helsinki declaration and its later amendments or comparable ethical standards. 


\section{Appendix "For Online Publication"}

Table 5 Descriptive statistic over three analytical samples, divided between brothers and sister

\begin{tabular}{|c|c|c|c|c|c|c|c|c|c|c|}
\hline & \multicolumn{2}{|c|}{ Sample 1} & \multicolumn{2}{|c|}{ Sample 2} & \multicolumn{2}{|c|}{ Sample 3} & \multicolumn{2}{|c|}{$\begin{array}{l}\text { Sample } 2 \\
\text { (Brothers) }\end{array}$} & \multicolumn{2}{|c|}{$\begin{array}{l}\text { Sample } 2 \\
\text { (Sisters) }\end{array}$} \\
\hline & $\begin{array}{l}\text { Mean } \\
\text { s.d. }\end{array}$ & \#Obs & $\begin{array}{l}\text { Mean } \\
\text { s.d. }\end{array}$ & \#Obs & $\begin{array}{l}\text { Mean } \\
\text { s.d. }\end{array}$ & \#Obs & $\begin{array}{l}\text { Mean } \\
\text { s.d. }\end{array}$ & \#Obs & $\begin{array}{l}\text { Mean } \\
\text { s.d. }\end{array}$ & \#Obs \\
\hline Child's risk in traffic & $\begin{array}{l}4,03 \\
0,03\end{array}$ & 3504 & $\begin{array}{l}4,14 \\
0,05\end{array}$ & 1849 & $\begin{array}{l}3,90 \\
0,05\end{array}$ & 1655 & $\begin{array}{l}4,49 \\
0,05\end{array}$ & 1252 & $\begin{array}{l}3,41 \\
0,08\end{array}$ & 597 \\
\hline Child's risk in financial & $\begin{array}{l}5,06 \\
0,03\end{array}$ & 3504 & $\begin{array}{l}4,92 \\
0,04\end{array}$ & 1849 & $\begin{array}{l}5,22 \\
0,05\end{array}$ & 1655 & $\begin{array}{l}5,16 \\
0,05\end{array}$ & 1252 & $\begin{array}{l}4,41 \\
0,08\end{array}$ & 597 \\
\hline Child's risk in general & $\begin{array}{l}4,51 \\
0,03\end{array}$ & 3504 & $\begin{array}{l}4,50 \\
0,04\end{array}$ & 1849 & $\begin{array}{l}4,53 \\
0,05\end{array}$ & 1655 & $\begin{array}{l}4,74 \\
0,05\end{array}$ & 1252 & $\begin{array}{l}3,97 \\
0,08\end{array}$ & 597 \\
\hline \multicolumn{11}{|l|}{ Child's age } \\
\hline $18-29$ years & $\begin{array}{l}0,62 \\
0,01\end{array}$ & 3504 & $\begin{array}{l}0,78 \\
0,01\end{array}$ & 1849 & $\begin{array}{l}0,44 \\
0,01\end{array}$ & 1655 & $\begin{array}{l}0,77 \\
0,01\end{array}$ & 1252 & $\begin{array}{l}0,81 \\
0,02\end{array}$ & 597 \\
\hline 30-39 years & $\begin{array}{l}0,23 \\
0,01\end{array}$ & 3504 & $\begin{array}{l}0,18 \\
0,01\end{array}$ & 1849 & $\begin{array}{l}0,29 \\
0,01\end{array}$ & 1655 & $\begin{array}{l}0,19 \\
0,01\end{array}$ & 1252 & $\begin{array}{l}0,15 \\
0,01\end{array}$ & 597 \\
\hline 40-49 years & $\begin{array}{l}0,08 \\
0,00\end{array}$ & 3504 & $\begin{array}{l}0,03 \\
0,00\end{array}$ & 1849 & $\begin{array}{l}0,13 \\
0,01\end{array}$ & 1655 & $\begin{array}{l}0,03 \\
0,00\end{array}$ & 1252 & $\begin{array}{l}0,03 \\
0,01\end{array}$ & 597 \\
\hline $50-59$ years & $\begin{array}{l}0,04 \\
0,00\end{array}$ & 3504 & $\begin{array}{l}0,01 \\
0,00\end{array}$ & 1849 & $\begin{array}{l}0,07 \\
0,01\end{array}$ & 1655 & $\begin{array}{l}0,01 \\
0,00\end{array}$ & 1252 & $\begin{array}{l}0,01 \\
0,00\end{array}$ & 597 \\
\hline $60+$ years & $\begin{array}{l}0,03 \\
0,00\end{array}$ & 3504 & $\begin{array}{l}0,00 \\
0,00\end{array}$ & 1849 & $\begin{array}{l}0,060 \\
0,01\end{array}$ & 1655 & $\begin{array}{l}0,00 \\
0,00\end{array}$ & 1252 & $\begin{array}{l}0,00 \\
0,00\end{array}$ & 597 \\
\hline Child's average age & $\begin{array}{l}29,18 \\
0,19\end{array}$ & 3504 & $\begin{array}{l}25,05 \\
0,15\end{array}$ & 1849 & $\begin{array}{l}33,81 \\
0,32\end{array}$ & 1655 & $\begin{array}{l}25,31 \\
0,18\end{array}$ & 1252 & $\begin{array}{l}24,50 \\
0,28\end{array}$ & 597 \\
\hline \multicolumn{11}{|l|}{ Child's gender } \\
\hline Male & $\begin{array}{l}0,73 \\
0,01\end{array}$ & 3504 & $\begin{array}{l}0,68 \\
0,01\end{array}$ & 1849 & $\begin{array}{l}0,78 \\
0,01\end{array}$ & 1655 & $\begin{array}{l}1,00 \\
0,00\end{array}$ & 1252 & $\begin{array}{l}0,00 \\
N A\end{array}$ & 597 \\
\hline Female & $\begin{array}{l}0,27 \\
0,01\end{array}$ & 3504 & $\begin{array}{l}0,32 \\
0,01\end{array}$ & 1849 & $\begin{array}{l}0,22 \\
0,01\end{array}$ & 1655 & $\begin{array}{l}0,00 \\
N A\end{array}$ & 1252 & $\begin{array}{l}1,00 \\
0,00\end{array}$ & 597 \\
\hline \multicolumn{11}{|c|}{ Main explanatory variables } \\
\hline Traffic & $\begin{array}{l}2,46 \\
0,03\end{array}$ & 2414 & $\begin{array}{l}2,56 \\
0,04\end{array}$ & 1723 & $\begin{array}{l}2,21 \\
0,05\end{array}$ & 691 & & & & \\
\hline Financial & $\begin{array}{l}3,95 \\
0,04\end{array}$ & 2414 & $\begin{array}{l}4,17 \\
0,05\end{array}$ & 1723 & $\begin{array}{l}3,40 \\
0,07\end{array}$ & 691 & & & & \\
\hline General & $\begin{array}{l}3,37 \\
0,04\end{array}$ & 2414 & $\begin{array}{l}3,50 \\
0,04\end{array}$ & 1723 & $\begin{array}{l}3,03 \\
0,07\end{array}$ & 691 & & & & \\
\hline \multicolumn{11}{|l|}{ Father's risk attitudes } \\
\hline Traffic & $\begin{array}{l}3,11 \\
0,05\end{array}$ & 1503 & $\begin{array}{l}3,19 \\
0,05\end{array}$ & 1391 & $\begin{array}{l}2,15 \\
0,11\end{array}$ & 112 & & & & \\
\hline Financial & $\begin{array}{l}4,43 \\
0,05\end{array}$ & 1503 & $\begin{array}{l}4,51 \\
0,05\end{array}$ & 1391 & $\begin{array}{l}3,46 \\
0,19\end{array}$ & 112 & & & & \\
\hline General & $\begin{array}{l}3,97 \\
0,05\end{array}$ & 1503 & $\begin{array}{l}4,06 \\
0,05\end{array}$ & 1391 & $\begin{array}{l}2,92 \\
0,15\end{array}$ & 112 & & & & \\
\hline \multicolumn{11}{|l|}{ Socio-economic status } \\
\hline Low education & $\begin{array}{l}0,88 \\
0,01\end{array}$ & 2414 & $\begin{array}{l}0,84 \\
0,01\end{array}$ & 1723 & $\begin{array}{l}0,96 \\
0,01\end{array}$ & 691 & & & & \\
\hline Primary education & $\begin{array}{l}0,09 \\
0,01\end{array}$ & 2414 & $\begin{array}{l}0,11 \\
0,01\end{array}$ & 1723 & $\begin{array}{l}0,03 \\
0,01\end{array}$ & 691 & & & & \\
\hline Secondary education & 0,04 & 2414 & 0,05 & 1723 & 0,01 & 691 & & & & \\
\hline
\end{tabular}


Table 5 (continued)

\begin{tabular}{|c|c|c|c|c|c|c|c|c|c|c|}
\hline & \multicolumn{2}{|c|}{ Sample 1} & \multicolumn{2}{|c|}{ Sample 2} & \multicolumn{2}{|c|}{ Sample 3} & \multicolumn{2}{|c|}{$\begin{array}{l}\text { Sample } 2 \\
\text { (Brothers) }\end{array}$} & \multicolumn{2}{|c|}{$\begin{array}{l}\text { Sample } 2 \\
\text { (Sisters) }\end{array}$} \\
\hline & $\begin{array}{l}\text { Mean } \\
\text { s.d. }\end{array}$ & \#Obs & $\begin{array}{l}\text { Mean } \\
\text { s.d. }\end{array}$ & \#Obs & $\begin{array}{l}\text { Mean } \\
\text { s.d. }\end{array}$ & \#Obs & $\begin{array}{l}\text { Mean } \\
\text { s.d. }\end{array}$ & \#Obs & $\begin{array}{l}\text { Mean } \\
\text { s.d. }\end{array}$ & \#Obs \\
\hline \multirow{3}{*}{ University } & 0,00 & & 0,01 & & 0,00 & & & & & \\
\hline & 0,00 & 2414 & 0,00 & 1723 & 0,00 & 691 & & & & \\
\hline & 0,00 & & 0,00 & & 0,00 & & & & & \\
\hline \multicolumn{11}{|c|}{ Father's education level } \\
\hline \multirow[t]{2}{*}{ Low education } & 0,77 & 1503 & 0,76 & 1391 & 0,86 & 112 & & & & \\
\hline & 0,01 & & 0,01 & & 0,03 & & & & & \\
\hline \multirow[t]{2}{*}{ Primary education } & 0,14 & 1503 & 0,15 & 1391 & 0,13 & 112 & & & & \\
\hline & 0,01 & & 0,01 & & 0,03 & & & & & \\
\hline \multirow[t]{2}{*}{ Secondary education } & 0,07 & 1503 & 0,07 & 1391 & 0,02 & 112 & & & & \\
\hline & 0,01 & & 0,01 & & 0,01 & & & & & \\
\hline \multirow[t]{2}{*}{ University } & 0,02 & 1503 & 0,02 & 1391 & 0,00 & 112 & & & & \\
\hline & 0,00 & & 0,00 & & 0,00 & & & & & \\
\hline \multicolumn{11}{|c|}{ Household consumption 2014} \\
\hline \multirow[t]{2}{*}{ Food consumption } & $973^{\prime}$ & 3504 & $972^{\prime}$ & 1849 & 974 & 1655 & & & & \\
\hline & $10^{\prime}$ & & $13^{\prime}$ & & $17^{\prime}$ & & & & & \\
\hline \multirow{2}{*}{$\begin{array}{l}\text { Non-food } \\
\text { consumption }\end{array}$} & $1023^{\prime}$ & 3504 & $1088^{\prime}$ & 1849 & $952^{\prime}$ & & & & & \\
\hline & $12^{\prime}$ & & $18^{\prime}$ & & $16^{\prime}$ & 1655 & & & & \\
\hline \multicolumn{11}{|c|}{ Mother having bank account } \\
\hline \multirow[t]{2}{*}{ No bank account } & 0,90 & 2414 & 0,87 & 1723 & 0,98 & 691 & & & & \\
\hline & 0,01 & & 0,01 & & 0,01 & & & & & \\
\hline \multirow[t]{2}{*}{ Bank account } & 0,10 & 2414 & 0,13 & 1723 & 0,02 & 691 & & & & \\
\hline & 0,01 & & 0,01 & & 0,01 & & & & & \\
\hline Missing & 0,00 & 2414 & 0,00 & 1723 & 0,00 & 691 & & & & \\
\hline & 0,00 & & 0,00 & & 0,00 & & & & & \\
\hline Father having bank acce & unt & & & & & & & & & \\
\hline No bank account & 0,77 & 1503 & 0,76 & 1391 & 0,96 & 112 & & & & \\
\hline & 0,01 & & 0,01 & & 0,02 & & & & & \\
\hline Bank account & 0,23 & 1503 & 0,24 & 1391 & 0,04 & 112 & & & & \\
\hline & 0,01 & & 0,01 & & 0,02 & & & & & \\
\hline Missing & 0,00 & 1503 & 0,00 & 1391 & 0,00 & 112 & & & & \\
\hline & 0,00 & & 0,00 & & 0,00 & & & & & \\
\hline Household size & 10,89 & 3504 & 11,05 & 1849 & 10,71 & 1655 & & & & \\
\hline & 0,09 & & 0,12 & & 0,15 & & & & & \\
\hline Family structure & & & & & & & & & & \\
\hline Mother's age at birth & & & & & & & & & & \\
\hline 13-19 years & 0,10 & 3504 & 0,14 & 1849 & 0,06 & 1655 & & & & \\
\hline & 0,01 & & 0,01 & & 0,01 & & & & & \\
\hline 20-29 years & 0,33 & 3504 & 0,48 & 1849 & 0,16 & 1655 & & & & \\
\hline & 0,01 & & 0,01 & & 0,01 & & & & & \\
\hline 30-39 years & 0,20 & 3504 & 0,25 & 1849 & 0,13 & 1655 & & & & \\
\hline & 0,01 & & 0,01 & & 0,01 & & & & & \\
\hline $40+$ years & 0,07 & 3504 & 0,07 & 1849 & 0,07 & 1655 & & & & \\
\hline & 0,00 & & 0,01 & & 0,01 & & & & & \\
\hline Father's age at birth & & & & & & & & & & \\
\hline $13-19$ years & 0,00 & 3504 & 0,00 & 1849 & 0,00 & 1655 & & & & \\
\hline & 0,00 & & 0,00 & & 0,00 & & & & & \\
\hline 20-29 years & 0,08 & 3504 & 0,15 & 1849 & 0,01 & 655 & & & & \\
\hline & 0,00 & & 0,01 & & 0,00 & & & & & \\
\hline $30-39$ years & 0,18 & 3504 & 0,32 & 1849 & 0,03 & 1655 & & & & \\
\hline & 0,01 & & 0,01 & & 0,00 & & & & & \\
\hline $40+$ years & 0,16 & & 0,28 & & 0,04 & & & & & \\
\hline & 0,01 & & 0,01 & & 0,00 & & & & & \\
\hline
\end{tabular}


Table 5 (continued)

\begin{tabular}{|c|c|c|c|c|c|c|c|c|c|c|}
\hline & \multicolumn{2}{|c|}{ Sample 1} & \multicolumn{2}{|c|}{ Sample 2} & \multicolumn{2}{|c|}{ Sample 3} & \multicolumn{2}{|c|}{$\begin{array}{l}\text { Sample } 2 \\
\text { (Brothers) }\end{array}$} & \multicolumn{2}{|c|}{$\begin{array}{l}\text { Sample } 2 \\
\text { (Sisters) }\end{array}$} \\
\hline & $\begin{array}{l}\text { Mean } \\
\text { s.d. }\end{array}$ & \#Obs & $\begin{array}{l}\text { Mean } \\
\text { s.d. }\end{array}$ & \#Obs & $\begin{array}{l}\text { Mean } \\
\text { s.d. }\end{array}$ & \#Obs & $\begin{array}{l}\text { Mean } \\
\text { s.d. }\end{array}$ & \#Obs & $\begin{array}{l}\text { Mean } \\
\text { s.d. }\end{array}$ & \#Obs \\
\hline \multicolumn{11}{|l|}{ Mother's religion } \\
\hline \multirow[t]{2}{*}{ Catholic } & 0,28 & 1723 & 0,28 & 1723 & 0,22 & 691 & & & & \\
\hline & 0,01 & & 0,01 & & 0,02 & & & & & \\
\hline \multirow[t]{2}{*}{ Muslim } & 0,59 & 1723 & 0,59 & 1723 & 0,66 & 691 & & & & \\
\hline & 0,01 & & 0,01 & & 0,02 & & & & & \\
\hline \multirow[t]{2}{*}{ Protestant } & 0,08 & 1723 & 0,08 & 1723 & 0,06 & 691 & & & & \\
\hline & 0,01 & & 0,01 & & 0,01 & & & & & \\
\hline \multirow[t]{2}{*}{ Animism } & 0,05 & 1723 & 0,05 & 1723 & 0,06 & 691 & & & & \\
\hline & 0,01 & & 0,01 & & 0,01 & & & & & \\
\hline \multicolumn{11}{|l|}{ Father's religion } \\
\hline \multirow[t]{2}{*}{ Catholic } & 0,27 & 1391 & 0,27 & 1391 & 0,25 & 112 & & & & \\
\hline & 0,01 & & 0,01 & & 0,04 & & & & & \\
\hline \multirow[t]{2}{*}{ Muslim } & 0,58 & 1391 & 0,58 & 1391 & 0,64 & 112 & & & & \\
\hline & 0,01 & & 0,01 & & 0,05 & & & & & \\
\hline \multirow[t]{2}{*}{ Protestant } & 0,07 & 1391 & 0,07 & 1391 & 0,02 & 112 & & & & \\
\hline & 0,01 & & 0,01 & & 0,01 & & & & & \\
\hline \multirow[t]{2}{*}{ Animism } & 0,07 & 1391 & 0,07 & 1391 & 0,09 & 112 & & & & \\
\hline & 0,01 & & 0,01 & & 0,03 & & & & & \\
\hline \multicolumn{11}{|c|}{ Mother's marital status } \\
\hline \multirow[t]{2}{*}{ Single } & 0,00 & 1723 & 0,00 & 1723 & 0,01 & 691 & & & & \\
\hline & 0,00 & & 0,00 & & 0,00 & & & & & \\
\hline Married & 0,82 & 1723 & 0,82 & 1723 & 0,26 & 691 & & & & \\
\hline & 0,01 & & 0,01 & & 0,02 & & & & & \\
\hline Divorced & 0,01 & 1723 & 0,01 & 1723 & 0,02 & 691 & & & & \\
\hline & 0,00 & & 0,00 & & 0,01 & & & & & \\
\hline Widowed & 0,16 & 1723 & 0,16 & 1723 & 0,71 & 691 & & & & \\
\hline & 0,01 & & 0,01 & & 0,02 & & & & & \\
\hline Father's marital & & & & & & & & & & \\
\hline Single & 0,00 & 1391 & 0,00 & 1391 & 0,00 & 112 & & & & \\
\hline & 0,00 & & 0,00 & & 0,00 & & & & & \\
\hline Married & 0,96 & 1391 & 0,96 & 1391 & 0,94 & 112 & & & & \\
\hline & 0,00 & & 0,00 & & 0,02 & & & & & \\
\hline Divorced & 0,00 & 1391 & 0,00 & 1391 & 0,02 & 112 & & & & \\
\hline & 0,00 & & 0,00 & & 0,01 & & & & & \\
\hline Widowed & 0,03 & 1391 & 0,03 & 1391 & 0,04 & 112 & & & & \\
\hline & 0,00 & & 0,00 & & 0,02 & & & & & \\
\hline Health & & & & & & & & & & \\
\hline Mother's health & & & & & & & & & & \\
\hline past days) & & & & & & & & & & \\
\hline Not sick & 0,71 & 1723 & 0,71 & 1723 & 0,77 & 691 & & & & \\
\hline & 0,01 & & 0,01 & & 0,02 & & & & & \\
\hline Sick & 0,29 & 1723 & 0,29 & 1723 & 0,23 & 691 & & & & \\
\hline & 0,01 & & 0,01 & & 0,02 & & & & & \\
\hline Father's health & days) & & & & & & & & & \\
\hline Not sick & 0,71 & 1391 & 0,71 & 1391 & 0,73 & 112 & & & & \\
\hline & 0,01 & & 0,01 & & 0,04 & & & & & \\
\hline Sick & 0,29 & 1391 & 0,29 & 1391 & 0,27 & 112 & & & & \\
\hline & 0,01 & & 0,01 & & 0,04 & & & & & \\
\hline Mother smoking & & & & & & & & & & \\
\hline Don't smoke & 0,88 & 1723 & 0,88 & 1723 & 0,82 & 691 & & & & \\
\hline & 0,01 & & 0,01 & & 0,01 & & & & & \\
\hline Smoke & 0,12 & 1723 & 0,12 & 1723 & 0,18 & 691 & & & & \\
\hline
\end{tabular}


Table 5 (continued)

\begin{tabular}{|c|c|c|c|c|c|c|c|c|c|c|}
\hline & \multicolumn{2}{|c|}{ Sample 1} & \multicolumn{2}{|c|}{ Sample 2} & \multicolumn{2}{|c|}{ Sample 3} & \multicolumn{2}{|c|}{$\begin{array}{l}\text { Sample } 2 \\
\text { (Brothers) }\end{array}$} & \multicolumn{2}{|c|}{$\begin{array}{l}\text { Sample } 2 \\
\text { (Sisters) }\end{array}$} \\
\hline & $\begin{array}{l}\text { Mean } \\
\text { s.d. }\end{array}$ & \#Obs & $\begin{array}{l}\text { Mean } \\
\text { s.d. }\end{array}$ & \#Obs & $\begin{array}{l}\text { Mean } \\
\text { s.d. }\end{array}$ & \#Obs & $\begin{array}{l}\text { Mean } \\
\text { s.d. }\end{array}$ & \#Obs & $\begin{array}{l}\text { Mean } \\
\text { s.d. }\end{array}$ & \#Obs \\
\hline & 0,01 & & 0,01 & & 0,01 & & & & & \\
\hline \multicolumn{11}{|l|}{ Father smoking } \\
\hline \multirow[t]{2}{*}{ Don't smoke } & 0,78 & 1391 & 0,78 & 1391 & 0,72 & 112 & & & & \\
\hline & 0,01 & & 0,01 & & 0,04 & & & & & \\
\hline \multirow[t]{2}{*}{ Smoke } & 0,22 & 1391 & 0,22 & 1391 & 0,28 & 112 & & & & \\
\hline & 0,01 & & 0,01 & & 0,04 & & & & & \\
\hline \multicolumn{11}{|l|}{ Residential zone } \\
\hline \multirow[t]{2}{*}{ Urban } & 0,59 & 1849 & 0,59 & 1849 & 0,47 & 1655 & & & & \\
\hline & 0,01 & & 0,01 & & 0,01 & & & & & \\
\hline \multirow[t]{2}{*}{ Rural } & 0,41 & 1849 & 0,41 & 1849 & 0,53 & 1655 & & & & \\
\hline & 0,01 & & 0,01 & & 0,01 & & & & & \\
\hline
\end{tabular}

The Table shows mean, standard deviation and number of observations for sibling, parents and household characteristics for rounds 3 and 4, for Sample 1-3. The variable Sick was not collected in the fourth round. In this paper Sample 2 is used as the analytical sample. Sample 3 includes older siblings with limited information from their parents, and Sample 1 includes Sample 2 and 3. For baseline estimates of sibling correlations in risk attitudes for samples 1 and 3 see Table 2 in Sepahvand and Shahbazian (2018)

Open Access This article is licensed under a Creative Commons Attribution 4.0 International License, which permits use, sharing, adaptation, distribution and reproduction in any medium or format, as long as you give appropriate credit to the original author(s) and the source, provide a link to the Creative Commons licence, and indicate if changes were made. The images or other third party material in this article are included in the article's Creative Commons licence, unless indicated otherwise in a credit line to the material. If material is not included in the article's Creative Commons licence and your intended use is not permitted by statutory regulation or exceeds the permitted use, you will need to obtain permission directly from the copyright holder. To view a copy of this licence, visit http://creativecommons.org/licenses/by/4.0/.

\section{References}

Adermon, A., Gunnarsson, K.: The role of the immediate and extended family in the formation of wealth: evidence from Sweden. Unpublished Manuscript, Uppsala University, Department of Economics (2017)

Almlund, M., Duckworth, A.L., Heckman, J., Kautz, T.: Personality psychology and economics. In: Handbook of the Economics of Education, pp. 1-181. Elsevier (2011)

Andersson, O., Holm, H.J., Tyran, J.-R., Wengström, E.: Risk aversion relates to cognitive ability: preferences or noise? J. Eur. Econ. Assoc. 14(5), 1129-1154 (2016)

Anger, S., Schnitzlein, D.D.: Cognitive skills, non-cognitive skills, and family background: evidence from sibling correlations. J. Popul. Econ. 30(2), 591-620 (2017)

Aparicio-Fenoll, A., Oppedisano, V.: Should I stay or should I go? Sibling effects in household formation. Rev. Econ. Househ. 14(4), 1007-1027 (2016)

Beauchamp, J.P., Cesarini, D., Johannesson, M.: The psychometric and empirical properties of measures of risk preferences. J. Risk Uncertain. 54(3), 203-237 (2017)

Becker, G., Tomes, N.: Human capital and the rise and fall of families. J. Labor Econ. 4(3), 1-39 (1986)

Benin, M.H., Johnson, D.R.: Sibling similarities in educational attainment: s comparison of like-sex and crosssex sibling pairs. Sociol. Educ. 11-21 (1984)

Björklund, A., Jäntti, M.: Intergenerational income mobility in Sweden compared to the United States. Am. Econ. Rev. 87(5), 1009-1018 (1997) 
Björklund, A., Jäntti, M.: How important is family background for labor-economic outcomes? Labour Econ. 19(4), 465-474 (2012)

Björklund, A., Jäntti, M.: Intergenerational mobility, intergenerational effects, sibling correlations, and equality of opportunity: a comparison of four approaches. Research in Social Stratification and Mobility. 100455, (2020)

Björklund, A., Eriksson, T., Jäntti, M., Raaum, O., Österbacka, E.: Brother correlations in earnings in Denmark, Finland, Norway and Sweden compared to the United States. J. Popul. Econ. 15(4), 757-772 (2002)

Björklund, A., Jäntti, M., Lindquist, M.J.: Family background and income during the rise of the welfare state: brother correlations in income for Swedish men born 1932-1968. J. Public Econ. 93(5-6), 671-680 (2009)

Björklund, A., Lindahl, L., Lindquist, M.J.: What more than parental income, education and occupation? An exploration of what Swedish siblings get from their parents. The BE Journal of Economic Analysis \& Policy. 10(1), (2010)

Black, S.E., Devereux, P.J.: Recent developments in intergenerational mobility. Handbook of Labor Economics. 4, 1487-1541 (2011)

Black, S.E., Devereux, P.J., Salvanes, K.G.: Why the apple doesn't fall far: understanding intergenerational transmission of human capital. Am. Econ. Rev. 95(1), 437-449 (2005)

Blanden, J., Gregg, P., Macmillan, L.: Intergenerational persistence in income and social class: the effect of within-group inequality. Journal of the Royal Statistical Society: Series A (Statistics in Society). 176(2), 541-563 (2013)

Bonin, H., Dohmen, T., Falk, A., Huffman, D., Sunde, U.: Cross-sectional earnings risk and occupational sorting: the role of risk attitudes. Labour Econ. 14(6), 926-937 (2007)

Borghans, L., Duckworth, A.L., Heckman, J.J., Ter Weel, B.: The economics and psychology of personality traits. J. Hum. Resour. 43(4), 972-1059 (2008)

Bredtmann, J., Smith, N.: Inequalities in educational outcomes: how important is the Family? Discussion Paper No. 10286, IZA, Bonn. (2016)

Brunello, G.: Absolute risk aversion and the returns to education. Econ. Educ. Rev. 21(6), 635-640 (2002)

Caliendo, M., Fossen, F.M., Kritikos, A.S.: Risk attitudes of nascent entrepreneurs-new evidence from an experimentally validated survey. Small Bus. Econ. 32(2), 153-167 (2009)

Camerer, C.F., Dreber, A., Forsell, E., Ho, T.-H., Huber, J., Johannesson, M., Kirchler, M., Almenberg, J., Altmejd, A., Chan, T.: Evaluating replicability of laboratory experiments in economics. Science. 351(6280), 1433-1436 (2016)

Canning, D., Raja, S., Yazbeck, A.S.: Africa's Demographic Transition: Dividend or Disaster? The World Bank (2015)

Cattell, M.G.: Models of old age among the Samia of Kenya: family support of the elderly. J. Cross-Cult. Gerontol. 5(4), 375-394 (1990)

Chadwick, L., Solon, G.: Intergenerational income mobility among daughters. Am. Econ. Rev. 92(1), 335-344 (2002)

Charness, G., Gneezy, U., Imas, A.: Experimental methods: eliciting risk preferences. J. Econ. Behav. Organ. 87, 43-51 (2013)

Conley, D., Glauber, R.: All in the family?: family composition, resources, and sibling similarity in socioeconomic status. Res> Soc. Stratif. Mobil. 26(4), 297-306 (2008)

Cramer, J.S., Hartog, J., Jonker, N., Van Praag, C.M.: Low risk aversion encourages the choice for entrepreneurship: an empirical test of a truism. J. Econ. Behav. Organ. 48(1), 29-36 (2002)

Croson, R., Gneezy, U.: Gender differences in preferences. J. Econ. Lit. 47(2), 448-474 (2009)

de Walque, D.: Risking your Health: Causes, Consequences, and Interventions to Prevent Risky Behaviors. World Bank Publications (2013)

Ding, X., Hartog, J., Sun, Y.: Can we measure individual risk attitudes in a survey? Discussion Paper No. 4807, IZA, Bonn (2010)

Dohmen, T., Falk, A., Huffman, D., Sunde, U., Schupp, J., Wagner, G.G.: Individual risk attitudes: measurement, determinants, and behavioral consequences. J. Eur. Econ. Assoc. 9(3), 522-550 (2011)

Dohmen, T., Falk, A., Huffman, D., Sunde, U.: The intergenerational transmission of risk and trust attitudes. Rev. Econ. Stud. 79(2), 645-677 (2012)

Donkers, B., Melenberg, B., Van Soest, A.: Estimating risk attitudes using lotteries: a large sample approach. J. Risk Uncertain. 22(2), 165-195 (2001)

Dreber, A., Pfeiffer, T., Almenberg, J., Isaksson, S., Wilson, B., Chen, Y., Nosek, B.A., Johannesson, M.: Using prediction markets to estimate the reproducibility of scientific research. Proc. Natl. Acad. Sci. 112(50), 15343-15347 (2015)

Dustmann, C., Fasani, F., Meng, X., Minale, L.: Risk attitudes and household migration decisions. Centro Studi Luca d'Agliano Development Studies Working Paper, (423) (2017) 
Emran, M.S., Shilpi, F.: Gender, geography, and generations: intergenerational educational mobility in postreform India. World Dev. 72, 362-380 (2015)

Emran, M. S., Shilpi, F.: Economic approach to intergenerational mobility: measures, methods, and challenges in developing countries. WIDER Working Paper 2019/98. Helsinki: UNU-WIDER (2019)

Emran, M.S., Jiang, H., Shilpi, F.: Gender bias and intergenerational educational mobility: theory and evidence from China and India. Unpublished manuscript. (2020)

Emran, M.S., Greene, W., Shilpi, F.: When measure matters: coresidency, truncation bias, and intergenerational mobility in developing countries. J. Hum. Resour. 53(3), 589-607 (2018)

Eriksson, K.H., Hjalmarsson, R., Lindquist, M.J., Sandberg, A.: The importance of family background and neighborhood effects as determinants of crime. J. Popul. Econ. 29(1), 219-262 (2016)

Fafchamps, M., Pender, J.: Precautionary saving, credit constraints, and irreversible investment: theory and evidence from serniarid India. J. Bus. Econ. Stat. 15(2), 180-194 (1997)

Fernández, R., Fogli, A., Olivetti, C.: Mothers and sons: preference formation and female labor force dynamics. Q. J. Econ. 119(4), 1249-1299 (2004)

Fraser-Mackenzie, P., Sung, M.-C., Johnson, J.E.V.: Toward an understanding of the influence of cultural background and domain experience on the effects of risk-pricing formats on risk perception. Risk Anal. 34(10), 1846-1869 (2014)

Gimenez-Nadal, J.I., Molina, J.A., Yu, Z.: Intergenerational mobility of housework time in the United Kingdom. Rev. Econ. Househ. 1-27 (2014)

Grönqvist, E., Öckert, B., Vlachos, J.: The intergenerational transmission of cognitive and non-cognitive abilities. J. Hum. Resour. (2016). https://doi.org/10.3368/jhr.52.4.0115-6882R1

Guiso, L., Paiella, M.: The role of risk aversion in predicting individual behaviors. Bank of Italy economic working paper no. 546 (2005)

Hardeweg, B., Menkhoff, L., Waibel, H.: Experimentally validated survey evidence on individual risk attitudes in rural Thailand. Econ. Dev. Cult. Chang. 61(4), 859-888 (2013)

Harrison, G.W., Humphrey, S.J., Verschoor, A.: Choice under Uncertainty in Developing Countries. CeDEx Discussion Paper. The University of Nottingham (2005)

Holmlund, H.: Estimating long-term consequences of teenage childbearing an examination of the siblings approach. J. Hum. Resour. 40(3), 716-743 (2005)

INSD: Document Projet De L'Enquête Multisectorielle Continue. Institut National de la Statistique et de la Démographie, Burkina Faso, 1-27 (2013)

INSD: Rapport Enquête multisectorielle continue 2014: Profil de pauvreté et d'inégalités. Institut National de la Statistique et de la Démographie, Burkina Faso, 1-90 (2015a)

INSD: Rapport Enquête multisectorielle continue 2014: Caractéristiques sociodémographiques de la population. Institut National de la Statistique et de la Démographie, Burkina Faso, 1-55 (2015b)

INSD: Projections démographiques des communes du Burkina Faso de 2007 à 2020. Institut National de la Statistique et de la Démographie, Burkina Faso, 1-1860 (2017)

Jäntti, M., Jenkins, S.P.: Income mobility. In: Handbook of Income Distribution, pp. 807-935. Elsevier (2015)

Jencks, C., Bartlett, S., Corcoran, M., Crouse, J., Eaglesfield, D., Jackson, G., McClelland, K., Mueser, P., Olneck, M., Schwarts, J., Ward, S., Williams, J.: Who Gets Ahead? The Determinants of Economic Success in America. Basic Books, New York (1979)

Jin, J., He, R., Gong, H., Xu, X., He, C.: Farmers' risk preferences in rural China: measurements and determinants. Int. J. Environ. Res. Public Health. 14(7), 713 (2017)

Kimball, M.S., Sahm, C.R., Shapiro, M.D.: Risk preferences in the PSID: individual imputations and family covariation. Am. Econ. Rev. 99(2), 363-368 (2009)

Koski, A., Clark, S., Nandi, A.: Has child marriage declined in sub-Saharan Africa? An analysis of trends in 31 countries. Popul. Dev. Rev. 43(1), 7-29 (2017)

Liebenehm, S., Waibel, H., Menkhoff, L.: Changes in risk attitudes and vulnerability to idiosyncratic and covariate shocks-evidence from panel household data in Thailand and Vietnam. Unpublished manuscript, Leibniz University Hannover (2015)

Lindquist, M., Sol, J., van Praag, C.M., Vladasel, T.: On the origins of entrepreneurship: evidence from sibling correlations. Discussion Paper No. 10278, IZA, Bonn (2016)

Lönnqvist, J.-E., Verkasalo, M., Walkowitz, G., Wichardt, P.C.: Measuring individual risk attitudes in the lab: task or ask? An empirical comparison. J. Econ. Behav. Organ. 119, 254-266 (2015)

Mason, P.L.: Intergenerational mobility and interracial inequality: the return to family values. Econ. Soc. 46(1), 51-80 (2007)

Mazumder, B.: Sibling similarities and economic inequality in the US. J. Popul. Econ. 21(3), 685-701 (2008)

Mood, C.: More than money: social class, income, and the intergenerational persistence of advantage. Sociol. Sci. 4, 263-287 (2017) 
Mood, C., Jonsson, J.O., Bihagen, E.: Socioeconomic persistence across generations: cognitive and noncognitive processes. In: Ermisch, J., M. Jäntti, and T. Smeeding (eds.), Cross-National Research on the Intergenerational Transmission of Advantage. New York: Russell Sage (2012)

Nelson, J.A.: Not-so-strong evidence for gender differences in risk taking. Fem. Econ. 22(2), 114-142 (2016)

Newman, J.S.: Women of the World: Sub-Saharan Africa. US Department of Commerce, Bureau of Census (1984)

Peil, M.: Family help for the elderly in Africa: a comparative assessment. South. Afr. J. Gerontol. 4(2), 26-32 (1995)

Rabe-Hesketh, S., Skrondal, A., Pickles, A.: Maximum likelihood estimation of limited and discrete dependent variable models with nested random effects. J. Econ. 128(2), 301-323 (2005)

Schnitzlein, D.D.: How important is the family? Evidence from sibling correlations in permanent earnings in the USA, Germany, and Denmark. J. Popul. Econ. 27(1), 69-89 (2014)

Sepahvand, M.H.: Essays on risk attitudes in sub-Saharan Africa. Economic Studies 178, Uppsala University, Department of Economics (2019)

Sepahvand, M.H., Shahbazian, R.: Sibling correlation in risk attitudes: evidence from Burkina Faso. Working paper 2018:6, Uppsala University, Department of Economics (2018)

Sepahvand, M.H., Shahbazian, R.: Individual's risk attitudes in Sub-Saharan Africa: determinants and reliability of self-reported risk in Burkina Faso. Forthcoming The African Reivew of Economics and Finance. (2020a)

Sepahvand, M.H., Shahbazian, R.: Intergenerational transmission of risk attitudes in Burkina Faso. Empir. Econ. (2020b). https://doi.org/10.1007/s00181-020-01857-9

Solon, G.: Intergenerational mobility in the labor market. In: Handbook of Labor Economics, pp. 1761-1800. Elsevier (1999)

Solon, G., Corcoran, M., Gordon, R., Laren, D.: A longitudinal analysis of sibling correlations in economic status. J. Hum. Resour. 26, 509-534 (1991)

Tabellini, G.: The scope of cooperation: values and incentives. Q. J. Econ. 123(3), 905-950 (2008)

Vieider, F.M., Lefebvre, M., Bouchouicha, R., Chmura, T., Hakimov, R., Krawczyk, M., Martinsson, P.: Common components of risk and uncertainty attitudes across contexts and domains: evidence from 30 countries. J. Eur. Econ. Assoc. 13(3), 421-452 (2015)

Weber, E.U., Blais, A.-R., Betz, N.E.: A domain-specific risk- attitude scale: measuring risk perceptions and risk behaviors. J. Behav. Decis. Mak. 15(4), 263-290 (2002)

Wölbert, E., Riedl, A.: Measuring time and risk preferences: reliability, stability, domain specificity. CESifo working paper no. 4339 (2013)

Yesuf, M., Bluffstone, R.A.: Poverty, risk aversion, and path dependence in low-income countries: experimental evidence from Ethiopia. Am. J. Agric. Econ. 91(4), 1022-1037 (2009)

Yeung, W.J., Duncan, G.J., Hill, M.S.: Putting fathers back in the picture: parental activities and children's adult outcomes. Marriage Fam. Rev. 29(2-3), 97-113 (2000)

Publisher's Note Springer Nature remains neutral with regard to jurisdictional claims in published maps and institutional affiliations. 